\title{
O posesivo non concordado en galego e en castelán de Galicia como mudanza sintáctica en curso
}

\author{
Carme Silva-Domínguez ${ }^{1}$
}

Recibido: 12 de marzo de 2021 / Aceptado: 15 de novembro de 2021

Resumo. O presente artigo ofrece unha análise de dous tipos de pronome posesivo non concordado que son posibles en galego e no castelán de Galicia. Por unha banda, o coñecido avance do paradigma cara a estruturas nucleadas por un adverbio de lugar, do tipo de diante miña. Pola outra, o menos descrito, mais tamén frecuente, posesivo carente de concordancia en locucións adverbiais de significado locativo e outras. Trátase de exemplos como ao lado súa e semellantes. A análise consiste nun baleirado dos corpus TILG, CORGA e CORILGA para o galego, ESLORA para o castelán de Galicia. Mediante eles dáse conta da cronoloxía do fenómeno e do poder explicativo dos seguintes factores no avance da innovación: a persoa gramatical, o tipo de adverbio ou locución adverbial, o grao de animación do antecedente, entre outros. Arguméntase, así mesmo, en favor da interpretación da mudanza como cambio desde abaixo, e descríbense os dous intentos de operar un cambio desde arriba sobre a innovación. Finalmente, achéganse evidencias en favor da interpretación do cambio sintáctico como endóxeno e procúrase unha explicación novidosa do fenómeno peculiar que representa a selección do xénero feminino para a forma de posesivo en ambos os sistemas lingüísticos.

Palabras chave: pronome posesivo; frase adverbial; mudanzas desde arriba/abaixo; innovación sintáctica; mudanza sintáctica; interferencia sintáctica; galego; castelán de Galicia.

\section{[es] El posesivo no concordado en gallego y en castellano de Galicia como cambio sintáctico en curso}

Resumen. El presente artículo ofrece un análisis de dos tipos de pronombre posesivo no concordado que son posibles en gallego y en castellano de Galicia. Por un lado, el conocido avance del paradigma hacia estructuras nucleadas por un adverbio de lugar, del tipo de diante miña. Por la otra, el menos descrito, pero también frecuente, posesivo carente de concordancia en locuciones adverbiales de significado locativo y otros. Se trata de ejemplos como ao lado súa y semejantes. El análisis consiste en un vaciado de los corpus TILG, CORGA, CORILGA para el gallego, ESLORA para el castellano de Galicia. A través de estos se da cuenta de la cronología del fenómeno y de la relevancia de factores tales como la persona gramatical, el tipo de adverbio o locución adverbial del que se trate, el grado de animación del antecedente, etc., y su poder explicativo en el avance de la innovación. Se argumenta, asimismo, en favor de la interpretación del cambio como cambio desde abajo, y se describen los dos intentos de operar un cambio desde arriba sobre la innovación. Finalmente, se propone una explicación novedosa del fenómeno peculiar que representa la selección del género femenino para la forma de posesivo en ambos sistemas lingüísticos.

Palabras clave: pronombre posesivo; frase adverbial; cambios desde arriba/desde abajo; innovación sintáctica; cambio sintáctico; interferencia sintáctica; gallego; castellano de Galicia.

\section{[en] Possessive without Concordance in Galician and in Galician Spanish as a Syntactic Change in Progress}

Abstract. This article offers an analysis of two forms of the so-called Possessive without agreement that are possible in Galician and in Galician Spanish. First of all, it deals with the well-known progress of the possessive paradigm to structures that are nucleated by an adverb of place, like diante miña. Secondly, the constructions like ao lado súa, where the (2) possessive pronoun appears without agreement and whose meaning can be locative, and others are also studied. The analysis consists of (3) accessing and using the TILG, CORGA and CORILGA corpus for Galician, and the ESLORA corpus for Galician Spanish. Aspects which are described are the chronology of the phenomenon and the relevance of factors such as the grammatical person, the kind of adverb or adverbial locution, the level of animation in the antecedent:

1 Universidade de Santiago de Compostela. Departamento de Filoloxía Galega.

Correo-e: mdocarme.silva@usc.es; ORCID: https://orcid.org/0000-0002-2839-9901. 
all of them are analysed to explain their ability to promote innovation. Arguments supporting the interpretation of the remodelling as a change from below are provided, and two attempts to operate a change from above in the innovation are also described. Finally, the article offers evidence for the interpretation of the linguistic remodelling as endogenous; the peculiar phenomenon that consists of the selection of the feminine genre for the possessive form in both linguistic systems is studied as well.

Keywords: Possessive Pronoun; Adverbial Phrase; Changes from Above/from Below; Syntactic Innovation; Syntactic Change; Syntactic Interference; Galician; Galician Spanish.

Sumario. 1. Introdución. 1.1. Breve aproximación aos corpus analizados. 1.2. As preguntas da investigación. 2. Na procura dun marco teórico para a interpretación da innovación: a diferenciación entre mudanzas desde abaixo e mudanzas desde arriba e o tránsito da variación ao cambio. 3. Análise da fase 1 ou de innovación. 3.1. Unha hipótese acerca da orixe do fenómeno: a equivalencia sintáctica e alternancia distribucional entre POS e Fprep como constituíntes da frase nominal. 3.2. O primeiro movemento innovador: unha mudanza desde abaixo ligada ás construcións de valor locativo. 3.3. A hipótese do castelán como orixe da innovación. 3.4. A morfoloxía da innovación: a selección da forma feminina para POS. 4. Análise da fase II ou de expansión: a difusión de POS no ámbito da frase adverbial. 4.1. Aspectos metodolóxicos. 4.2. Análise do comportamento das formas 1-5 e mais xunto/ xunta (formas 6). 4.2.1. Predominio cuantitativo e cualitativo de POS en feminino: o masculino, idiolectal ou talvez dialectal. 4.2.2. As documentacións máis antigas ( $\operatorname{anos} 30,50$ e 70 do século $\mathrm{XX}$ ): formas 1-2 e un único testemuño do tipo 4. 4.2.3. Anos 80 do século XX: importante avance cuantitativo nas formas 1 e 2, diversificación cualitativa da innovación de cara aos grupos 3, 4 e 6. 5 . Aparición de estruturas de base nominal non concordadas con locucións adverbiais nucleadas por redor, carón, lado e rente (tipos 5 e 6). 5.1. Unha alternancia tradicional entre Fprep e POS (tipos 5, 6): a innovación consiste no emprego do feminino. 5.2. A extensión da innovación a outras unidades e outros ámbitos semánticos: emprego da variante non concordada coas locucións nucleadas por través e favor. 6. Análise dos corpus CORILGA e ESLORA. 6.1. CORILGA. 6.2. ESLORA. 7. Síntese final dos datos e proposta de interpretación destes desde a perspectiva da mudanza sintáctica. 8 . Referencias bibliográficas.

Como citar: Silva-Domínguez, C. (2021): “O posesivo non concordado en galego e en castelán de Galicia como mudanza sintáctica en curso", en Madrygal. Revista de Estudios Gallegos 24, pp. 191-216, DOI: http://dx.doi. org/10.5209/madr.80240.

\section{Introdución}

O presente artigo ocúpase da análise, no galego dos séculos XX e XXI e no castelán de Galicia, de diversas situacións de variación relacionadas co pronome posesivo (de aquí en diante POS), que se introduce como modificador en distintas estruturas sintácticas ata erixirse en alternativa estrutural a de + pronome persoal (de aquí en diante Fprep). Trátase de exemplos como os que se reproducen deseguido, en que os/as falantes teñen a oportunidade de escolleren entre (1) ou (2) e entre (3) ou (4) $)^{2}$ :

(1) Ese día tiven que ir para casa nun coche do 092 porque os autopatróns estaban $d e$ trás de min (xornal A Nosa Terra, 1993; prensa).

(2) Entran detrás miña o can e o gato (S. de Toro, Tic Tac, 1993; novela).

(3) Quedeime durmido e cando despertei vin que estaba un meniño a carón de $\min (\mathrm{M}$. Rodríguez López, Reencontro coa aldea; 1983; novela).

(4) A carón miña hai unha laxe con esguíos cervos de aire, pousados na pedra (A. Conde, Memoria de Noa, 1981; novela).

Como denominación xenérica no estudo da forma innovadora escóllese a etiqueta posesivo non concordado, pois esta, a ausencia de concordancia en xénero e número, é a característica que presentan en común as estruturas (2) e (4). A non concordancia débese, na primeira delas, á condición de adverbio do elemento nuclear; na segunda, ao feito de que o posesivo apareza fixado en feminino, a pesar de a estrutura reclamar da unidade o xénero contrario. Outros casos de posesivo non concordado que se detectan no diasistema do español contemporáneo - por exemplo, Casanova (2020) centrado na importación de POS como elemento complementar da cláusula- quedan fóra da análise, por non se documentaren nos corpus estudados.

\subsection{Breve aproximación aos corpus analizados}

A análise examinará a alternancia entre POS e Fprep nas estruturas seleccionadas tal e como esta se presenta nos corpus TILG, CORGA, CORILGA e ESLORA (este último para o castelán de Galicia) ${ }^{3}$. A accesibilidade que estas catro ferramentas de análise achegan foi o criterio fundamental para optarmos polo seu emprego; porén, as características peculiares de

2 Non se achegan os números de páxina dos exemplos, pois estes foron extraídos dos corpus estudados e tal información non está presente neles.

3 De acordo coa información que figura na súa páxina web, o corpus TILG (http://ilg.usc.es/TILG/gl) “compila máis de 3.000 documentos producidos entre 1612 e 2013 e contén arredor de 30 millóns de formas gráficas, lematizadas 
cada un dos corpus provocan que o exame dos resultados non poida ser conxunto para todos eles. Os dous primeiros céntranse en textos escritos, por máis que cada un presente unha cata na oralidade, e de maneira conxunta fan posible que se documente a evolución cuantitativa e cualitativa da alternancia estudada ao longo de todo o século XX e primeiras décadas do XXI. $O$ terceiro, de reducido tamaño aínda, achega fundamentalmente materiais do galego oral, en tanto que o derradeiro permite documentar a situación de determinadas variedades do castelán de Galicia mediante mostras de lingual oral obtidas a partir de entrevistas semidirixidas.

A importancia cuantitativa dos materiais procedentes do exame dos corpus TILG e ESLORA será aproveitada para imprimir unha orientación estatística ao estudo da alternancia, mais só naqueles puntos en que a rendibilidade desta o aconselle. Os datos que se extraen de CORILGA e, sobre todo, de ESLORA, son máis exiguos canto ao seu número, mais ofrecen interesantes desenvolvementos de natureza cualitativa e permiten elaborar unha hipótese conxunta para ambas as linguas en contacto.

A análise da alternancia entre opcións estruturais, así como do cambio lingüístico asociada a esta, adoita realizarse nas últimas décadas mediante mostras de lingua diferentes das testemuñadas na escrita. Sabemos que a mudanza espontánea xorde na oralidade, e só nun segundo momento, e non sempre, avanza cara a rexistros máis formais da lingua. Porén, a exploración das posibilidades que ofrecen os corpus TILG e CORGA en análises de corte variacionista realizadas desde unha perspectiva histórica, como a que emprendemos no momento actual, non pode ser posta en dúbida, con independencia da súa necesaria complementación con materiais procedentes de rexistros de lingua oral, achegados neste estudo por CORILGA e ESLORA.

\subsection{As preguntas da investigación}

Partimos da consideración como innovadoras das variantes con POS non concordado, tanto na frase adverbial como naquelas locucións en que se introduce a unidade sen acordo en xénero co núcleo substantivo. Aínda que se achegarán algúns datos do debate acerca da interpretación do fenómeno como de orixe endóxena ou esóxena, procurarase non centrar a análise nesta cuestión. Interésanos fundamentalmente a descrición pormenorizada de como os corpus recollen a variación analizada, en resposta ás seguintes cuestións:

1.2.1. A respecto da presenza de POS na frase preposicional do galego, tentamos saber como é o proceso de expansión da variante innovadora na escrita do século XX (Cando aparece? A que inventario de unidades afecta? Cal é a importancia cuantitativa de POS fronte á opción más tradicional de Fprep?).

1.2.2. Canto ás estruturas exemplificadas en (2), examinarase a posible existencia de variación de xénero en relación coa ocorrencia de POS (isto é, compararase a rendibilidade de diante meu e diante miña). Sabido é que este aspecto é un dos máis investigados no diasistema do español, idioma en que a innovación se presenta xeograficamente dividida no relativo á ocorrencia do posesivo nun ou noutro xénero ${ }^{4}$.

1.2.3. Que saibamos, a escolla dunha morfoloxía feminina para o posesivo na frase preposicional só foi obxecto de dous recentes intentos de explicación para o castelán (véxase infra, apartado 3.4). A nosa investigación tratará de

e anotadas con etiquetas morfosintácticas". Os materiais do corpus son esencialmente literarios. Pola súa parte, CORGA (http://corpus.cirp.es/corga/) está composto tamén maioritariamente por textos escritos, aínda que as súas últimas versións incorporan tamén materiais procedentes da lingua oral dos medios de comunicación. A versión empregada consta dun total de 36.746 .902 palabras ortográficas etiquetadas automaticamente, e de 44.125.386 elementos gramaticais, cun subgrupo significativo de ambos sometido a un etiquetado manual. Todos os materiais foron producidos entre os anos 1975 e 2016. Canto aos corpus CORILGA (http://ilg.usc.es/corilga/) e ESLORA (http://eslora. usc.es/), ambos vinculados a equipos de investigación da Universidade de Santiago de Compostela, ofrecen materiais procedentes da lingua oral e son dun tamaño similar (110 horas de gravación en CORILGA, 80 en ESLORA). Porén, a metodoloxía de obtención dos datos e a cronoloxía destes son diversas: ESLORA achega entrevistas e gravacións realizadas entre 2007 e 2015, en tanto que a cronoloxía de CORILGA é diversa, pois inclúense desde testemuños de finais dos 60 a varias dos 80 e 90, xunto con outras semellantes ás do corpus español no seu arco temporal. Dada a súa moita menor envergadura, fronte a TILG e CORGA, empregaqrémolos para examinar as posibilidades de corroborar as hipóteses construídas sobre os materiais obtidos dos corpus máis grandes. Tamén se rendibilizarán os datos, achegados por ambos, acerca da localización xeográfica, xénero e nivel de estudos dos e as falantes.

4 Do interese que suscita o fenómeno dá conta a seguinte relación de traballos que abordan a cuestión do xénero do posesivo na frase adverbial: Salgado e Bouzouita (2017), Eddington (2017), Marttinen Larsson e Álvarez López (2018). Marttinen Larsson e Bouzouita (2018), Hoff (2020), Casanova (2020) e Bouzouita (no prelo). 
examinar a posible validez das hipóteses nos corpus galegos, así como de construír vías alternativas de explicación do fenómeno.

1.2.4. Finalmente, e dado que no apartado 2 do traballo realizaremos unha abordaxe á variación sintáctica a partir das propostas de, entre outros, Labov (2001) e Del Barrio (2018), procuraremos unha lectura para o fenómeno de acordo coas hipóteses destes autores, e máis en concreto da diferenciación conceptual entre indicadores, marcadores e estereotipos achegada por estes.

Queda fóra dos obxectivos da análise a posibilidade de examinar o comportamento doutros tipos de texto en relación coa innovación que nos ocupa. Porén, gustaríanos neste punto romper unha lanza en favor da necesidade de trasladar ao mundo dixital o estudo sincrónico de fenómenos deste tipo, na liña das propostas de De Benito Moreno e Estrada Arráez (2016, 2018) e á vista da existencia de exemplos como os que seguen, tomados de Twitter: (especialmente 2001), diferentes autores desenvolveron propostas de aplicación que teñen como obxectivo modelizar o cambio lingüístico. Neste noso traballo tentaremos dar forma aos datos de acordo con elementos tomados de tales modelos explicativos, especialmente seguindo a de Del Barrio (2018: 36-48) mais coa introdución de elementos procedentes dos/ as autores/as que se citan.

Cando un/unha falante ou grupo de falantes promove, de xeito consciente ou non, unha mudanza lingüística, esta consiste en xeral na introdución dunha nova posibilidade (fonético-fonolóxica, estrutural, semántica, léxica, etc.), que pasa a alternar a respecto da variante orixinal. Atopámonos, daquela, na primeira fase do cambio lingüístico: unha situación de competencia entre opcións tras o xurdimento dunha innovación (Ibid.: 40). A mudanza pode aparecer por expresividade (termo xenérico co que o autor se refire a aqueles cambios que suceden de maneira espontánea, non dirixida,

(5)

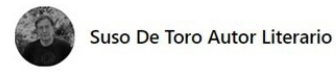

1 de Oct de 2020 - Q Diante miña pola rúa camiña unha muller nova, está morena do sol do verán, "bronceada". Inmediatamente crúzome cunha moza tamén morena, mais o seu moreno é natural, de seu, unha das tantas posibilidades dos cruces de persoas con cores de pel distintos. Alégrame pensar que a muller "bronceada" puido disfrutar duns días de lecer e de sol gratuito..

(1).0 Anxa G. Refoxo e 231 máis

16 comentarios

(6)

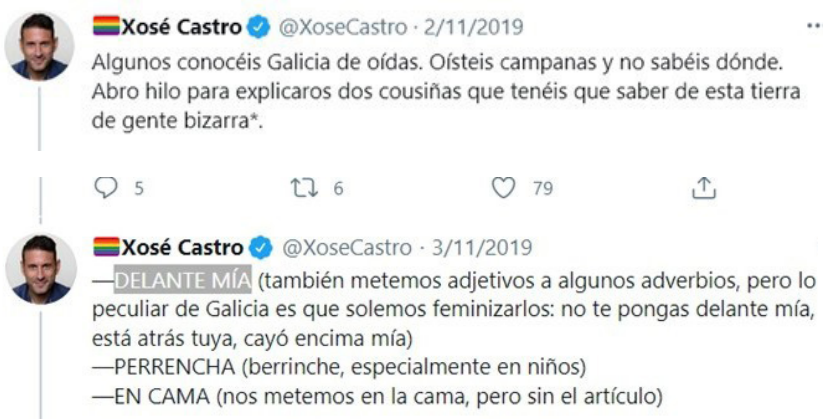

2. Na procura dun marco teórico para a interpretación da innovación: a diferenciación entre mudanzas desde abaixo e mudanzas desde arriba e o tránsito da variación ao cambio

A partir dos seminais conceptos sinalados no título, procedentes dos traballos de W. Labov mesmo por causa da interferencia doutra lingua $^{5}$ ) ou por elaboración ("se trataría de un fenómeno consciente, normativo, prestigioso, propio de los ámbitos de la 'distancia comunicativa"'; Ibid.: 41). Esta última situación prodúcese naqueles procesos que implican a creación de novas tradicións discursivas (Jacob e Kabatek 2001) para un idioma, novos

5 Por exemplo e para o portugués do Brasil, a orixe da notable cantidade de mudanzas que diferencian a norma popular da norma culta e, por suposto, da norma padrón, é situada por Lucchesi $(2009,2012,2013)$ na influencia das linguas de contacto do idioma no proceso de conquista, tanto daquelas propias dos pobos precolombinos como das achegadas polo repoboamento do territorio por parte de poboacións de orixe africana. 


\begin{tabular}{|l|l|}
\hline \multicolumn{2}{|c|}{ Fase I. Innovación } \\
\hline "Desde abaixo": cambios por expresividade & Endóxenos \\
\cline { 2 - 2 } & $\begin{array}{l}\text { Esóxenos (provocados por interferencia, converxencia, influen- } \\
\text { cia de linguas de substrato, etc.) }\end{array}$ \\
\hline "Desde arriba": cambios por elaboración & Endóxenos \\
\cline { 2 - 2 } & $\begin{array}{l}\text { Esóxenos (provocados pola imitación de tradicións discursivas } \\
\text { desenvolvidas orixinariamente noutras linguas) }\end{array}$ \\
\hline
\end{tabular}

Cadro 1. Representación da innovación e tipos. Elaboración propia a partir dos autores citados

tipos de textos, previamente non explorados e que son elaborados adoito por imitación doutras linguas ${ }^{6}$, ou logo da intervención motivada e explícita sobre recursos endóxenos. Desde o noso punto de vista, na diferenciación entre mudanzas provocadas inicialmente por innovación e aqueloutras xustificadas na elaboración subxace un primeiro emprego dos conceptos labovianos de mudanza desde abaixo e mudanza desde arriba, que serán de novo utilizados para a explicación das seguintes etapas do cambio.

En síntese, o proceso innovador vese reflectido no cadro 1, en que se completa o modelo de Del Barrio (2018) mediante unha segunda columna e botando man da diferenciación entre cambios endóxenos e esóxenos.

Un segundo momento no proceso de cambio das linguas consiste na difusión, isto é, a propagación da mudanza fóra do seu espazo orixinal. Neste punto Del Barrio (2018: 43) toma de Labov (2001) a diferenciación entre indicadores, marcadores e estereotipos ${ }^{7}$ :

Los cambios "desde abajo" o por expresividad que se sitúan por debajo del nivel consciente no pueden estar controlados por los hablantes y no presentan variaciones estilísticas [...]: suelen iniciarse en un grupo social como indicadores y se encuentran estratificados de acuerdo a factores externos (edad, región, clase social). A medida que avanzan, estos cambios pueden adquirir relevancia social y estar condicionados por variaciones discursivas o contextuales; se convierten en marcadores. Si la evaluación del resto de los hablantes de una comunidad es positiva, el cambio será adoptado por los miembros más prestigiosos y aceptado en situaciones de mayor formalidad. Si, por el contrario, recibe una valoración negativa, el rasgo variable queda estigmatizado y se convierte en un estereotipo. (Del Barrio 2018: 43)

Conde Silvestre (2007: 130-131) debuxa o percurso entre a primeira e segunda e terceira categorías conceptuais mediante procesos de avaliación exercidos por falantes doutros grupos sociais e status diverso. O paso de indicadores a marcadores supón a difusión da innovación máis alá do seu grupo social orixinal (dialecto, clase, grupo de idade, etc.) En palabras do autor, un indicador é unha forma "todavía independiente del contexto de uso, es decir, no responde a ninguna pauta de variación contextual o estilística en el discurso de quienes la utilizan". Outro elemento que define o indicador consiste en que "muestra valores más elevados en los hablantes más jóvenes, quienes mantienen la dirección del cambio por efecto de la presión interna ejercida por sus pares".

Finalmente, nunha terceira fase denominada polo autor de adopción, o conxunto de falantes dunha comunidade consuma a mudanza lingüística. A este momento chégase logo de que se avalíe positivamente, e posteriormente se acepte, ben a forma innovadora ben a variante conservadora (no caso de que a mudanza fracase). Unha proposta de ordenamento das fases segunda e terceira do cambio lingüístico pode atoparse no cadro 2 :

6 Intervencións innovadoras sobre as linguas, debidas ao contacto lingüístico, son por exemplo as detectables no portugués e tendentes á converxencia sintáctica co castelán. Véxase Döhla (2014) sobre o avance do marcado de obxecto ata o século XVIII, e Martins (2015) sobre a colocación do clítico no portugués quiñentista. Por outra parte, as mudanzas na sintaxe do castelán do XV estudadas por Pons Rodríguez (2006) son debidas, en opinión da autora, á influencia do latín pola importación de novos tipos de textos tomados desta lingua.

7 Lucchesi (2012: 59) utiliza esta terminoloxía para dar conta da variación entre aplicación ou non aplicación da regra de concordancia no portugués brasileiro rural e urbano. 


\begin{tabular}{|c|c|c|}
\hline \multicolumn{2}{|c|}{ Fase II. As variantes A e B coexisten como sinónimas } & $\begin{array}{l}\text { Fase III: as variantes A e B non coexisten } \\
\text { como sinónimas }\end{array}$ \\
\hline \multicolumn{2}{|c|}{$\begin{array}{l}\text { Fase II.0. Como indicador, os/as falantes emprégano de maneira } \\
\text { non tematizada e inconsciente. Por algún feito de difusión, o } \\
\text { indicador avanza socialmente e deixa de ser propio dun grupo } \\
\text { específico (xeográfico, sociolóxico, de idade, etc.) }\end{array}$} & $\begin{array}{l}\text { Posibilidade } 1 \text { e situación esperable: a } \\
\text { variante promovida polos sectores de maior } \\
\text { status social (xeralmente a conservadora) } \\
\text { triunfa. Nos sectores sociais intermedios } \\
\text { prodúcese a hipercorrección (Conde } \\
\text { Silvestre 2007: 130-131). }\end{array}$ \\
\hline \multicolumn{2}{|c|}{$\begin{array}{l}\text { Fase II.1. Ao ser adoptado por individuos pertencentes a outros } \\
\text { grupos diferentes daquel en que se xera o cambio, estes fan un uso } \\
\text { tematizado (estilisticamente) do trazo: transfórmano en marcador. }\end{array}$} & $\begin{array}{l}\text { Posibilidade 2: a variante promovida polos } \\
\text { sectores populares triunfa se conta con pres- } \\
\text { tixio encuberto (Labov 2001: 196; Conde } \\
\text { Silvestre 2007: } 131 \text {; Del Barrio 2018: 45). }\end{array}$ \\
\hline \multirow{2}{*}{$\begin{array}{l}\text { Fase II.2a. A avaliación } \\
\text { (explícita, mediante a gramática, } \\
\text { ou implícita) determina que } \\
\text { o marcador sexa empregado } \\
\text { en contextos non formais, } \\
\text { ditaminando que non procede na } \\
\text { linguaxe coidada: o marcador } \\
\text { carece de prestixio e non progresa } \\
\text { cara a novos grupos de falantes e } \\
\text { novos ámbitos de uso. }\end{array}$} & \multirow{2}{*}{$\begin{array}{l}\text { Fase II.2b. A avaliación } \\
\text { (explícita, mediante a } \\
\text { gramática, ou implícita) } \\
\text { determina que o marcador } \\
\text { sexa empregado en contextos } \\
\text { formais, ditaminando que } \\
\text { procede na linguaxe coidada: } \\
\text { o marcador posúe prestixio e } \\
\text { progreso cara a novos grupos } \\
\text { de falantes e ámbitos de uso. }\end{array}$} & $\begin{array}{l}\text { Posibilidade 3: as dúas variantes poderían } \\
\text { subsistir se deixan de ser sinónimas. }\end{array}$ \\
\hline & & $\begin{array}{l}\text { Para calquera das posibilidades: a variante } \\
\text { descartada pode manterse en forma de } \\
\text { estereotipo e posuír un prestixio encuberto } \\
\text { que posibilite o seu mantemento en certos } \\
\text { contextos (e que podería determinar, a } \\
\text { medio prazo, o seu avance e a inversión da } \\
\text { mudanza). }\end{array}$ \\
\hline A innovación retrocede & A innovación avanza & $\begin{array}{l}\text { A innovación consúmase, resemantízase ou } \\
\text { queda estereotipificada }\end{array}$ \\
\hline
\end{tabular}

Cadro 2. Transformación dun trazo de indicador a marcador ou estereotipo (mudanzas "desde abaixo"). Elaboración propia a partir dos autores citados

Unha vez realizada a análise da mudanza lingüística que nos ocupa a través dos corpus mencionados para o galego e para o castelán de Galicia, discutirase acerca da posibilidade de que a variante innovadora avanzase conceptualmente, desde a súa orixinaria condición de indicador cara á posición de marcador ou mesmo de estereotipo. Neste momento valoraranse así mesmo os intentos de gobernar o proceso de cambio (mudanzas desde arriba) e sinalarase o seu posible éxito á luz dos datos achegados polos corpus que se examinaron.

\section{Análise da fase 1 ou de innovación}

\subsection{Unha hipótese acerca da orixe do fenó- meno: a equivalencia sintáctica e alternan- cia distribucional entre POS e Fprep como constituíntes da frase nominal}

Retómase neste punto, de maneira resumida, a argumentación presentada en Silva Domínguez (1995 e 2020) para explicar a comparabilidade estrutural entre ambas as opcións e xustificar, deste xeito, o avance de POS cara ao espazo distribucional en orixe ocupado por Fprep. Dentro da frase nominal e nas persoas relacionadas co coloquio, a equivalencia de significados é total e resólvese co establecemento dunha distribución complementaria entre ambas, que beneficia a POS como modificador da xeneralidade de substantivos agás nalgúns deverbais, en que Fprep pode ser utilizada, secundariamente, para a expresión non da entidade que executa, senón que recibe a acción ${ }^{8}$. Velaquí un exemplo desta posibilidade excepcional:

(7) Todos míranme con ese coñecemento de min-de nós-nos ollos (M. C. Pavón Mauriz, Ruído Branco, 2011; relato breve) ${ }^{9}$

Por contra, na terceira/sexta persoa a frase preposicional achega unha vantaxe importante: as flexións de xénero e número do pronome persoal permiten unha mellor e máis segura localización do antecedente, polo que Fprep pode ser utilizada como estratexia supletoria naqueles

8 Cf. Silva Domínguez (1995: 7-ss.) para o exame dalgúns outros exemplos especiais, como os xerados pola estrutura cuantitativa a maioría de.

9 O exemplo pertence ao corpus CORGA, en que se constitúe como único caso de Fprep na complementación deste substantivo, fronte a 19 exemplos de POS anteposto e ningún posposto. 
exemplos en que o/a falante considera preciso ou conveniente indicar esta información para a determinación da anáfora. Unha mínima cata no corpus CORGA permite sinalar a case total preponderancia cuantitativa de POS con substantivos tan comúns coma casa $^{10}$, en tanto que deverbais como coñecemento non presentan pautas diferenciais no seu uso en terceira/sexta persoas a respecto das sinaladas anteriormente para as persoas asociadas ao coloquio ${ }^{11}$. No rexistro escrito, por tanto, o posesivo parece ser a opción predominante mesmo naquelas persoas, a terceira e a sexta, en cuxo emprego os/as falantes poderían extraer un beneficio da utilización da opción analítica.

No entanto, valería a pena observar máis en detalle como se comporta a alternancia construtiva noutros rexistros de lingua. Falta por saber (e para isto precísanse corpus doutro tipo, ou o deseño de ferramentas experimentais que permitan comprobalo) se aquelas variedades diafásicas máis ligadas á oralidade presentan comportamentos diferenciais canto á alternancia, en contornos nominais, entre POS e Fprep nas persoas terceira/sexta ${ }^{12}$.

\subsection{O primeiro movemento innovador: un- ha mudanza desde abaixo ligada ás constru- cións de valor locativo}

Unha vez examinada a distribución de espazos existente entre Fprep e POS dentro da frase nominal, postúlase que a innovación se produce cando o paradigma dos posesivos accede a un espazo que inicialmente ten vedado, dada a natureza non substantiva do seu núcleo: a frase adverbial. Xorde neste punto a alternancia entre estruturas reflectida nos exemplos (1) e (2) anteriormente reproducidos.
Como vía de explicación do acceso de POS a un contorno sintáctico en que orixinariamente non está permitido, Silva Domínguez (1995) postula, a partir de autores/as anteriores/as ocupados/as na descrición do español, a importancia daquelas locucións adverbiais cuxo núcleo é unha unidade orixinariamente pertencente á clase substantiva (a carón de, a rente(s) de e similares). A proximidade distribucional entre ambos os tipos de construcións pode explicar o movemento desde as primeiras, en que o posesivo está admitido como parte da complementación do nome, ás segundas, en que inicialmente non é posible o emprego desta unidade. En Silva Domínguez (2020) retómase a mesma liña explicativa, mais coa adición do concepto de analoxía para o tratamento da mudanza. Neste mesmo traballo destácase, así mesmo, a condición de transformación atípica que caracteriza a esta no contexto xeral da deriva do latín ás linguas románicas, por canto supón a substitución dun recurso analítico por outro sintético ${ }^{13}$.

Así presentada a innovación, postúlase que esta responde aos trazos que se atribuíron anteriormente aos chamados cambios desde abaixo ou por expresividade (cf. supra, cadro 1 e parágrafos inmediatamente anteriores) aínda que, segundo veremos deseguido, no seu proceso de expansión a mudanza foi obxecto de dúas tentativas de cambio desde arriba, normativamente explicitados e en direccións contrarias.

\subsection{A hipótese do castelán como orixe da in- novación}

Sabido é que a introdución de POS na frase adverbial de valor locativo do español é obxecto nos últimos anos de intenso tratamento, tanto

10 O cómputo das estruturas que nos interesan é como segue: 2370 exemplos de a súa casa, 20 a casa del, 21 a casa dela, 7 a casa deles, 2 a casa delas.

11 Seu coñecemento ocorre no CORGA en 146 ocasións, en tanto que a opción analítica coñecemento del/dela/deles/ delas aparece en 14 ocorrencias ligada á estrutura ter coñecemento de, e nun exemplo máis paralelo con (5). Non se documenta, por tanto, a estratexia desambiguadora ligada ao emprego de Fprep fronte a POS neste substantivo.

12 En Silva Domínguez (1995: 9) achégase un indicio que podería ser explorado: nos textos escritos, case a metade de ocorrencias do paradigma dos posesivos (un 44, 41\%) corresponde ás persoas terceira/sexta, en tanto que nos materiais orais esta porcentaxe descende ata o 17,51\%. Podería ser, daquela, que na oralidade se priorizase a opción frástrica fronte ao posesivo, talvez pola indicada maior capacidade de achegar información para a determinación do antecedente fórico. Como apuntamento interlingüístico, cabe sinalar que a coexistencia entre ambas as opcións e a rendibilización da maior riqueza morfolóxica de Fprep na frase nominal deu lugar a estruturas reduplicadas do tipo de súa casa del/dela/deles/delas, posibles noutros momentos dentro do diasistema galego-portugués e comúns na actualidade en dialectos do castelán. Por outra banda, a norma popular do portugués do Brasil interpreta a comparabilidade entre POS e Fprep no seo da frase nominal botando man da eliminación (ou redución de posibilidades) daquel paradigma do contorno sintáctico referido (Lucchesi 2009: 495-ss.).

13 A substitución de estruturas concordadas por non concordadas é unha das mudanzas asociadas a procesos de cambio lingüístico extremadamente innovadores, como os de crioulización (Lucchesi 2009: 119-ss.). 
desde a perspectiva da análise descritiva como desde o punto de vista da prescrición gramatical. En Silva Domínguez (2020) revísase a bibliografía máis actual ata o momento sobre esta mudanza lingüística, no referido á importación de POS para estruturas locativas (Bertolotti 2014 e 2017; Salgado e Bouzouita 2017; Eddlington 2017; Marttinen Larsson e Álvarez López 2017; Marttinen Larsson e Bouzouita 2018; Marttinen Larsson 2018; Hoff 2020). A modo de resumo, no mencionado traballo conclúese que

(...) los resultados de estas investigaciones vienen a dibujar un panorama en el cual el avance del posesivo hacia estructuras de significado locativo es una realidad consumada en variedades coloquiales de español hablado de diversas zonas de España e Iberoamérica, y su frecuencia aumenta significativamente a partir de mediados del siglo XX, con una intensificación notable en los años 90. (Silva Domínguez 2020: 231)

O paralelismo existente entre o comportamento das variedades coloquiais de castelán e galego foi obxecto de dúas grandes liñas de análise, traducidas cada unha delas en súa proposta normativa ou intervención desde arriba: unha destínase a proscribir a mudanza pola súa orixe esóxena, a outra normaliza a presenza da innovación na frase adverbial ${ }^{14}$. Interesa neste momento examinar a argumentación que se emprega para aceptar ou rexeitar a condición de interferencia da mudanza.

Aínda que o desenvolvemento explícito da hipótese sexa máis tardío (non anterior aos primeiros anos do século XXI), son os/as partidarios/as de aceptar a natureza esóxena do cambio os que se manifestan con maior rotundidade. Freixeiro Mato (2001: 70) cualifica a innovación como "unha interferencia dobremente condenábel: como castelanismo e mais por se tratar dun vulgarismo na propia lingua de orixe". A afirmación non se sustenta en máis argumentos que os ligados á propia natureza innovadora da estrutura e á non presenza desta no portugués estándar europeo ${ }^{15}$. Cabe recordar, porén, que nos últimos tempos a lingüística de contacto ten detectado posibilidades diversas, diferentes da converxencia, para aquelas situacións en que dous ou máis sistemas lingüísticos están presentes nunha comunidade de fala. Por exemplo Braunmüller, Höder e Kühl (2014) recollen a estabilidade e a diverxencia, alén da converxencia, como resultados posibles en caso de contacto interlingüístico. Máis en concreto, en Kühl e Braunmüller (2014: 15) critícase a escasa concreción da definición que usualmente se dá do cambio inducido por contacto, "described in a rather vague manner as something that happens". A referida afirmación de Freixeiro Mato (2001) adoece en efecto dunha evidente vaguidade, pois non achega información acerca do mecanismo que explicaría o préstamo da estrutura dun sistema ao outro. Recórdese que con anterioridade, e coa mesma falta de modelo explicativo para o mecanismo da influencia, fora proposta tamén a posibilidade contraria como orixe da mudanza que nos ocupa (Meilán García 1998: 23) ${ }^{16}$.

Algúns anos antes de que a interferencia sintáctica xurdise como hipótese conformada (aínda que non explicada) para a penetración de POS no espazo de Fprep, os estudos gramaticais sobre a lingua galega parecían aceptar o fenómeno como alternativa estrutural non inducida por contacto. Nesta liña, Álvarez, Monteagudo e Regueira (1986: 220-221) maniféstanse do seguinte xeito:

14 Canto aos casos de non concordancia nominal que a acompañan e que se exemplifican en (4), nin unha nin outra proposta de interpretación se pronuncian explicitamente, mais podemos entender que son rexeitados por ambas, como sucedería en calquera outra situación en que se suspenda unha concordancia esperada. En calquera caso, non se alude a eles nos traballos que se sinalarán deseguido.

15 Aínda que Freixeiro Mato (2001) toma como base da súa análise a descrición desenvolvida en Silva Domínguez (1995) e atribúe a este último traballo a orixe da súa posición en termos de gramática normativa, debemos recordar que alí só se indica como posible criterio para a preferencia da opción non innovadora precisamente o seu carácter non tradicional, con independencia da orixe endóxena ou esóxena da mudanza.

16 Desde a perspectiva da sintaxe histórica, varios son os estudos que examinan procesos de converxencia e diverxencia no contacto castelán-portugués, con resultados non necesariamente conducentes á aproximación estrutural das dúas linguas. No volume anteriormente citado inclúese Döhla (2014) sobre o retroceso na marcaxe de obxecto, inducida polo castelán, no portugués dos séculos XVI-XVII. Por outra banda, Martins (2015) describe a existencia de dous dialectos, un máis influído polo castelán do que o outro, convivindo no portugués quiñentista a respecto da colocación dos clíticos. Estes traballos, e outros máis que se poderían citar, amosan ao noso xuízo a complexidade do fenómeno do contacto e dos seus posibles resultados, nun paradigma non determinista nin baseado na existencia dunha relación inexorable entre unha causa (o contacto) e un efecto (a mudanza inducida por interferencia). 
Cos adverbios relativos de lugar, o complemento formado pola preposición de mais un pronome persoal pode ser sustituído pola forma feminina singular do posesivo. Así, diante miña alterna con diante de min, detrás túa con detrás de ti, encima súa con encima del(es), dela(s), con encima de vostede(s) e con encima de si, debaixo nosa con debaixo de nós, enriba vosa con enriba de vós, etc.

Idéntico tratamento da cuestión é recollido en Álvarez Blanco e Xove (2002: 478). En ningún dos casos aparece mencionada a posibilidade de que a innovación sexa unha interferencia do castelán; simplemente se describe esta a partir da súa equivalencia coa construción tradicional, sen indicar dato ningún doutro tipo: maior ou menor frecuencia dunha ou outra posibilidades, ou preferencia por unha ou outra en termos cuantitativos, ou normativos, etc.

A ausencia, nos dous casos, dunha explicación acerca do mecanismo da mudanza lingüística, débese moi probablemente á condición de tratados gramaticais, na fronteira entre a descrición e a prescrición, que as caracteriza. $\mathrm{Na}$ procura de comprender o proceso, En Silva Domínguez (2020) postúlase que a segunda das propostas, a que analiza a innovación como independente do contacto, pode atopar un sustento no exame detido dos dous mapas do Atlas Lingüístico Galego (ALGa) referidos ao fenómeno $^{17}$. En efecto, é comunmente aceptado que o ALGa permite debuxar o estado do galego popular dos anos 70 na totalidade do territorio, e que nunha escala de interferencia a respecto do castelán, os/as informantes do ALGa representarían o punto de menor influencia desta lingua, dadas as características vitais que os definen $^{18}$. Pois ben, a análise dos mapas do ALGa que representan a variación que nos ocupa permite achegar as seguintes conclusións, ambas compatibles co carácter endóxeno da mudanza:

1. Aínda que só de maneira residual existen puntos en que a innovación se teña consumado totalmente, o número de lugares en que ambas as variantes son posibles é moi elevado especialmente no sur de Galicia, pois oscila entre o 36,3\% das localizacións da provincia de Pontevedra e o $10 \%$ da de Ourense. Alén disto, todas as áreas dialectais da lingua, mesmo aquelas máis conservadoras como o galego exterior, coñecen a innovación.

2. Canto á relación entre as localizacións que documentan a variante innovadora e os contornos das cidades, espazos tradicionalmente asociados á presenza dun maior número de individuos bilingües, en Silva Domínguez (2020: 235) conclúese que

no hay una correlación directa entre los puntos en los que los informantes manifiestan poder construir con posesivo en la frase preposicional locativa y los entornos de las ciudades, en los que el contacto entre variedades populares orales de gallego y castellano podría darse de manera más estrecha ya en los años 70 del siglo XX.

Ao noso xuízo, o principal atranco con que se topa a hipótese da interferencia consiste precisamente na constatación, a través do ALGa, de que falantes de variedades tradicionais da lingua, nacidos/as cara ás primeiras décadas do século XX e para os que se acepta como válida a súa escasa competencia en castelán (na liña, por exemplo, de Mariño Paz 2017), desenvolveron a innovación en diversos puntos do noso territorio lingüístico e sen aparente contacto co español oral. Perante a ausencia dun cerebro bilingüe que se constitúa en "the relevant locus of contact" (Matras 2009: 3), non resulta doado explicar a extensa e temperá difusión, no galego popular rural, dunha innovación ausente (proscrita) do castelán estándar.

Aínda máis, mesmo aceptando que o/a informante-tipo do ALGa fose xa, nos anos 70 do século XX, unha persoa bilingüe, coñecedor/a tanto da súa lingua materna como de variedades normativas do castelán, parece improbable que na súa competencia neste idioma entrasen tamén os rexistros coloquiais en que a innovación que nos ocupa estaba xa asentada naquela altura. Estudosos/as do contacto lingüístico en comunidades bilingües peninsulares como

17 Os numerados como 254 (detrás de min/detrás miña/detrás meu) e 255 (debaixo de nós/debaixo nosa/debaixo noso), en Álvarez Blanco (1995: 278-ss.).

18 En Fernández Rei (1990), o primeiro volume de material publicado a partir do ALGa, caracterízanse da seguinte maneira o informante tipo do proxecto: "Iletrado, de intelixencia natural, nativo do lugar igual cós seus pais e a súa muller, que non fose ó servizo militar, que non viaxase, que se exprese coa maior espontaneidade posible, sen defectos articulatorios". Porén, da sucinta descrición que se achega das persoas entrevistadas despréndese que si foron aceptadas informantes femininas, e que nalgunhas ocasións a resposta ao cuestionario non foi individual, senón froito do consenso dun grupo de persoas que se atopaban xuntas no momento en que a toma de datos foi realizada. 
Enrique-Arias (2010) teñen explicado como a transmisión (mediante a escola e os medios de comunicación tradicionais) dun español culto e conservador provoca un reducido contaxio de trazos lingüísticos innovadores, mesmo daqueles máis característicos das variedades coloquiais do español peninsular. Naturalmente, esta situación non é a que se dá na actualidade, en que as linguaxes electrónicas e certas tendencias de estilo no audiovisual, moito máis aberto hoxe á realidade oral das linguas, provocan que esteamos en contacto cunha grande diversidade de rexistros do idioma teito; porén, parece improbable un coñecemento xeneralizado dun trazo tan claramente innovador do castelán, alén de estigmatizado, por parte de persoas como as escollidas para seren informantes do ALGa na década dos 70 do século XX.

\subsection{A morfoloxía da innovación: a selección da forma feminina para POS}

$\mathrm{Na}$ lingua galega, a mudanza sintáctica que nos ocupa asóciase de maneira case exclusiva á forma de feminino singular do pronome posesivo, cunha presenza practicamente idiolectal do masculino (cf. infra, apartado 4.2.1). Porén, sabido é que en español a alternancia entre estruturas con masculino e con feminino coñece unha distribución dialectal que abrangue Europa e América e ten sido obxecto de análise en diversas achegas recentes (Eddlington 2017; Salgado e Bouzouita 2017; Hoff 2020). Delas despréndese un predominio global da forma do masculino, aínda que diversos dialectos do castelán peninsular (o de Galicia, o andaluz, parcialmente a lingua de Madrid) admiten, ou priorizan, a forma en feminino. Na nosa análise do corpus ESLORA veremos como o castelán de Galicia documentado nesta ferramenta unicamente permite localizar exemplos con morfoloxía coincidente coa característica do galego (cf. infra, apartado 6.2).

En español, son dúas as propostas que tentan explicar a introdución na estrutura da forma marcada canto ao xénero. Por unha banda, fálase de que talvez inflúa a necesidade de igualar o xénero do posesivo co do referente aludido (isto é, detrás mio cando o eu é un ser de xénero masculino, detrás mía cando é de xénero feminino). Por outra banda, lánzase a hipótese de que a feminización de POS na secuencia innovadora puido comezar naqueles adverbios que presentan algunha vogal /a/ no seu lexema (isto é, encima mía pero debajo mío) e estenderse posteriormente ao resto das unidades adverbiais. Porén, os dous traballos máis recentes que estudan o fenómeno desde a perspectiva do xénero de POS -Marttinen Larsson e Bouzouita (2018) en materiais procedentes de Andalucía e Hoff (2020), sobre a lingua do Twitter- non puideron constatar a validez de ningunha das dúas hipóteses.

Desde unha perspectiva nova e baseándonos en datos da lingua galega, desenvolvemos en Silva Domínguez (2020) unha proposta de explicación totalmente diferente, baseada na confluencia de tres feitos estruturais, un deles (o terceiro) hipotético e os outros dous ben coñecidos, descritos desde o XIX e en épocas posteriores propios de variedades arcaizantes da lingua ou fosilizados en paremias:

1. En primeiro lugar, o mantemento das posibilidades construtivas de determinadas unidades adverbiais (ou preposicionais), que se documentan no XIX e chegan ata o XXI sen preposición de ou a: por exemplo, diante/xunto/tras min, en lugar de diante/xunto/tras de min (cf. infra, apartado 4.2.3.1, para o exame do vigor cuantitativo da estrutura sen preposición nos corpus TILG e CORGA).

2. En segundo termo, a posibilidade que achegan os contornos preposicionais e as frases adverbiais de construír estruturas con posesivo e sen artigo, ben coñecida e documentada aínda na actualidade en dialectos conservadores (cf. Silva Domínguez 2002: 60). Combinado este factor co anterior atopan explicación estruturas como as seguintes, procedentes do corpus TILG:

(8) Diante vosa porta estará o gaiteiro // pra face-la festa, tud'o día enteiro (Manuel Lago González, Poesía, 1898; poesía)

(9) ¡Corre, rabo, tras teu amo! (lle dixo unha mai a un filliño qu'iba tras dela chorando) (Antonio Noriega Varela, Como falan os brañegos, 1928; glosario paremiolóxico)

3. O seguinte paso da nosa hipótese consiste na constatación de que a frase nominal caracterizada no apartado anterior pode perder o seu núcleo substantivo e quedar unicamente co posesivo. Esta opción construtiva, segundo veremos, comeza a documentarse nos corpus estudados desde os anos 30 do século XX, e o avance prodúcese en gran parte naquelas unidades que orixinariamente poden prescindir da preposición de, como é o caso de tras, cuxa documentación máis antiga no corpus TILG se reproduce deseguido: 
(10) Mais eu non vou tras túa coma un tigre de monte nin un león Xetulio para comerte a cachiños (Aquilino Iglesia Alvariño, Quinto Horacio Flacco: canciós, 1951; tradución de poesías do autor latino)

A orixe da entrada do posesivo na frase adverbial estaría, de acordo con esta formulación, na confluencia e confusión entre secuencias do tipo de diante min e diante miña + substantivo, confusión que permitiría xerar diante miña como opción innovadora. A hipótese permite ademais postular que a escolla da morfoloxía feminina na unidade se debe á maior proximidade entre min e miña do que entre min e meu: pode ser plausible unha confusión entre diante min e diante miña, mais é máis difícil supoñer que esta se dea entre diante min e diante meu. Repárese en que, de maneira indirecta, o castelán atoparía tamén bo encaixe na evolución proposta, especialmente no referido á súa característica vacilación entre masculino e feminino na innovación: en efecto, nesta lingua tanto mía como mio poden reclamarse próximas ao persoal mí e, neste sentido, delante mía e delante mío son igualmente plausibles.

Finalmente, a hipótese esbozada é compatible coa percepción de que a mudanza que traslada o posesivo á frase adverbial, como alternativa á frase preposicional con de, pode ser un proceso antigo, persistente en falas populares do galego, non necesariamente asociado á bilingüización masiva da sociedade e ao avance no coñecemento do castelán oral.
Así mesmo, a proposta encaixa con outros fenómenos de confusión ou confluencia entre persoal e posesivo que se producen no galego tradicional, como o que ten que ver coa xeración da estrutura de meu como alternativa, semanticamente marcada, a de min ou meu.

\section{Análise da fase II ou de expansión: a di- fusión de POS no ámbito da frase adverbial}

Unha vez examinadas as razóns que poderían explicar a innovación, pasamos a examinar a alternancia entre FPrep e POS a través dos datos que achegan os materiais indicados.

\subsection{Aspectos metodolóxicos}

O traballo toma como punto de partida a análise do fenómeno nos corpus TILG, CORGA, CORILGA e ESLORA a partir da descrición gramatical dos adverbios e locucións con valor espacial proposta en Álvarez Blanco e Xove (2002: 609-ss.), á que se engadiron diversas opcións estruturais ausentes deste traballo e que se explican en cada caso. Ofrecemos deseguido a relación de unidades que foron obxecto de procura nos corpus galegos, respectando a clasificación semántica orixinal. No cadro aparecen destacadas en grosa aquelas formas en que, dada a orixe nominal dos seus elementos nucleares, todos eles masculinos, a presenza de POS non debe interpretarse como innovación, sempre que esta unidade respecte a concordancia:

\begin{tabular}{|c|c|c|}
\hline \multirow{2}{*}{ Formas 1: posición no plano vertical } & Superior & riba ${ }^{19}$, derriba, enriba, encima ${ }^{20}$ \\
\hline & Inferior & baixo $^{21}$, debaixo, embaixo 22 \\
\hline \multirow{2}{*}{ Formas 2: posición no plano horizontal } & Anterior & diante \\
\hline & Posterior & detrás, atrás ${ }^{23}$, tras $^{24}$ \\
\hline \multirow{2}{*}{ Formas 3: localización no interior/exterior dun espazo ou corpo } & No interior & dentro \\
\hline & No exterior & fóra \\
\hline \multirow{2}{*}{ Formas 4: Afastamento/Proximidade a respecto dun punto } & Afastamento & $\operatorname{lonxe}^{25}$ \\
\hline & Proximidade & preto, perto $^{26}$, cerca $^{27}$, cabo $^{28}$ \\
\hline $\begin{array}{l}\text { Formas 5: localización no espazo total que rodea un corpo, ou } \\
\text { dun punto neste espazo }\end{array}$ & \multicolumn{2}{|c|}{ arredor, derredor, ao redor } \\
\hline $\begin{array}{l}\text { Formas 6: localización, no sentido horizontal ou vertical, en } \\
\text { proximidade ao lugar ocupado por outra entidade }\end{array}$ & \multicolumn{2}{|c|}{$\begin{array}{l}\text { a carón, ao carón, ao lado }{ }^{29}, \text { a rente }(s)^{30} \\
\text { xunto }^{31}, \text { xunta }^{32}\end{array}$} \\
\hline
\end{tabular}

Cadro 3. Relación de formas obxecto de estudo nos corpus TILG, CORGA e CORILGA

19 De acordo con Álvarez Blanco e Xove (2002: 615), as formas riba, fronte e baixo poden aparecer coa preposición previa por ou "sós e seguidos da preposición de (riba de, baixo de) ou a (fronte a)". No noso corpus ocorren modificadas tanto por Fprep como por POS.

20 Sometidas a unha situación de variación dialectal (Álvarez Blanco 1995: 348, mapa 322), en TILG e CORGA a rendibilidade de enriba é moi superior á do resto, cun $80 \%$ dos exemplos. Encima, forma compartida co castelán, 
Canto ao corpus ESLORA, examinaranse as versións ao castelán das formas galegas, así como algunha outra que poida ter o mesmo significado e careza de equivalencia no noso idioma.

Segundo se indicou anteriormente, a presenza do posesivo en masculino na estrutura das locucións adverbiais contidas no sexto tipo (formas 6), coa excepción neste grupo de xunto/xunta, non pode entenderse como propiamente excepcional, dada a natureza en orixe substantiva do seu elemento nuclear. Optamos por non considerar tampouco innovadoras estruturas do tipo de arredor meu/derredor meu, pois estas só na grafía son diferentes de a redor meu/de redor meu, con POS como modificador igualmente xustificado.

\subsection{Análise do comportamento das formas 1-5 e mais xunto/xunta (formas 6)}

Este apartado dedícase á análise das estruturas non concordadas, propiamente innovadoras, en que Fprep é substituída por POS a pesar da natureza non substantiva (senón adverbial ou, nalgúns casos, prepositiva) do primeiro elemento, na liña das exemplificadas en (2) e (10).

\subsubsection{Predominio cuantitativo e cualitativo de POS en feminino: o masculino, idiolectal ou talvez dialectal}

O corpus TILG achega un total de 357 exemplos innovadores, dos cales 301 presentan a forma en feminino $(84.3 \%)$ e 56 en masculino. En CORGA aumenta o número de POS en feminino e decrecen as formas de masculino: 581 dos primeiros $(95.2 \%)$ fronte a 29 dos segundos. Por outra banda, consideramos axeitada a etiqueta de idiolectal para os exemplos en masculino, pois todos eles agás catro (un en TILG, tres en CORGA) aparecen nas obras narrativas dun único autor, X. R. Martínez Oca, e entre os anos 1978 e 1993. Con todo, non se pode descartar a influencia das variedades populares en que POS en masculino está testemuñado no $\mathrm{ALGa}^{33}$.

aparece unicamente nun 6\% dos casos de TILG, mais xa avanza ata o 20\% en CORGA. CORILGA presenta, cun número moito menor de exemplos, un maior equilibrio entre variantes: $54 \%$ enriba, $43 \%$ encima .

21 Cf. supra, nota 19.

22 Aínda que embaixo (da mesma maneira ca abaixo) se sinala en Álvarez Blanco e Xove (2002: 616) como sen posibilidade de acoller Fprep na súa estrutura, o certo é que si se localizan exemplos no noso corpus de embaixo miña e semellantes. Porén, abaixo non se inclúe ao non localizarmos POS con esta unidade nos nosos corpus.

23 Aínda que en Álvarez Blanco e Xove (2002: 616) non consta este elemento na relación daqueles que admite Fprep, a presenza no noso corpus de exemplos tanto da estrutura tradicional como da innovadora esixía a súa análise.

24 A forma tras, dada a súa condición de preposición, non aparece na relación achegada polos autores. Porén, si é mencionada na abordaxe das posibilidades do posesivo en locucións prepositivas de valor locativo (Álvarez Blanco e Xove 2002: 478).

25 Estudouse tamén o castelanismo adaptado lexos.

26 Aínda que non é unha forma normativa na actualidade con este significado, si aparece como adverbio tanto en TILG como en CORGA.

27 Ausente da relación que presentan Álvarez Blanco e Xove (2002), incorpórase por presentar exemplos nos dous corpus estudados, e tamén porque o DRAG recolle a súa sinonimia total a respecto de preto (https://academia.gal/ dicionario/-/termo/busca/cerca).

28 A unidade non se recolle na gramática que serve de base á elaboración da táboa; porén, inclúese dada a súa sinonimia a respecto de preto-cerca e polo feito de localizárense exemplos innovadores en ambos os corpus.

29 A locución no aparece en la relación de adverbios, mais si é mencionada ao tratar as posibilidades de POS en estruturas adverbiais de valor locativo (Álvarez Blanco e Xove 2002: 478).

30 Só en sentido horizontal, advírtese na gramática.

31 Aínda que incluída na categoría preposición, o seu uso con posesivos aparece descrito en Álvarez Blanco e Xove (2002: 478, xunto de min / xunto miña). Por proximidade semántica inclúese no grupo de formas 6.

32 Aínda que a preposición non aparece na relación de formas que presentan as Normas ortográficas e morfolóxicas do idioma galego (Real Academia Galega e Instituto da Lingua 2003: apartado 19) pois é preferible, por ser máis conservadora, a locución analítica xunto $a$, no noso traballo incluímola por se documentar nos corpus acompañada tanto de Fprep como de POS.

33 X. R. Martínez Oca proporciona exemplos con POS en masculino cos seguintes adverbios: enriba, baixo,embaixo, diante, detrás, dentro, lonxe e preto. O único exemplo procedente de TILG de autor diferente é detrás noso, nunha narración do berciano Aquilino Poncelas, quen propositadamente reproduce nos seus escritos trazos característicos da súa fala. O ALGa documenta en zonas do galego exterior leonés a variante feminina. Canto a CORGA, Xosé Ramón Pena achega a mesma forma, e Vicente Araguas un lonxe noso, que podería relacionarse co debaixo noso localizado nas Pontes de García Rodríguez (cf. ALGa: 288, mapa 255) pola orixe en Ferrolterra de ambos os autores. Carlos García-González Durão proporciona un debaixo meu. 
En calquera caso, é evidente que o camiño de POS cara á frase adverbial se liga en galego case en exclusiva á variante feminina. Os corpus non permiten documentar tampouco un estadio inicial en que a alternancia entre ambos os xéneros apareza xustificada polo vocalismo do elemento nuclear, hipótese esta que, como se mencionou anteriormente (cf. supra, apartado 3.4), foi desenvolvida para a explicación da alternancia de xénero que se detecta no diasistema do español.

\subsubsection{As documentacións máis antigas (anos $30,50$ e 70 do século $X X)$ : formas 1-2 e un único testemuño do tipo 4}

Reprodúcense deseguido as seis primeiras documentacións da presenza de POS na estrutura, situadas nos anos 30 do século XX e procedentes do corpus TILG:

(11) Inda non recobrara o equelíbreo, e un que viña fuxíndolle a un «vello» dou volta por diante miña (M. García Barros, Contiños da terra, 1931; relato curto)

(12) Cada comensale tiña diante súa unha xarrada de bon viño (M. García Paz, Melodía, 1935; novela)

(13) O sole (...) tamén loguiño, se sinte renascer, xa gloirificándose, ao ver coma se abre o ceo diante súa pola mor de imporlle na testa un limbo santísimo de lus diviña (Id.)

(14) ((...) A pouco volve Xesteira, receoso, cuasi envergoñado). Xesteira: Debe matinar, Zabulón, van pasar por riba súa (...). Vostede soña, todos están en contra súa ( $\mathrm{L}$. Manteiga, Zabulón, 1935; teatro)

(15) E asina (...), non escutamos outra cousa que o zumbare das moscas, cando non temos que baixare as costas, si enriba nosa pegan as pigardas (M. García Paz, Melodía, 1935; novela)

(16) Unha ves que se achegara o lobo ao rabaño, o Prim, que estaba nun pucheiro, ripouse de cima, correndo rabioso detrás súa (Id.)

As tres primeiras obras en que se localiza a innovación achegan igualmente documentacións da variante Fprep: así, en Contiños da terra
(12) comparte espazo con diante del $^{34}$; (14) documéntase á par que riba del, aínda que neste caso hai unha diferenza notable: o antecedente do posesivo é [-humano] e [-animado] ${ }^{35}$. Por último, a obra de García Paz achega un número máis elevado de exemplos, e a variación nela localizada sintetízase no cadro 4:

\begin{tabular}{|l|l|}
\hline \multirow{5}{*}{ Enriba } & Enriba de min \\
\cline { 2 - 2 } & Enriba de il (2), de ila, de iles, de iles ${ }^{36}$ \\
\cline { 2 - 2 } & Enriba nosa \\
\hline \multirow{3}{*}{ Diante } & $\begin{array}{l}\text { Diante de si (sexta persoa) } \\
\text { Diante de il }\end{array}$ \\
\cline { 2 - 2 } & Diante súa (2) \\
\hline \multirow{2}{*}{ Detrás } & Detrás de il \\
\cline { 2 - 2 } & Detrás súa \\
\hline
\end{tabular}

Cadro 4: Fprep e POS en alternancia en García Paz, Melodía (1935)

As documentacións de POS en obras dos anos 30 parecen testemuñar unha fase de convivencia entre variante innovadora e Fprep que beneficia numericamente a segunda opción. Porén, con antecedentes [+humanos] ou humanizados, a innovación testemúñase en todas persoas ligadas ao coloquio coa excepción da quinta.

No primeiro ano da década dos 50, a tradución realizada por Aquilino Iglesia Alvariño das poesías de Horacio achega unha ocorrencia de POS con tras-anteriormente reproducida como (10)- e que convive coas alternativas tras $t i$ ( 3 ocorrencias) e tras de $t i^{37}$, ademais de con tras del; todos os exemplos, tanto os que se constrúen de xeito innovador como aqueles en que se opta pola estrutura tradicional, presentan antecedentes [+humanos]. Chamamos a atención acerca da convivencia, na mesma obra, de tras ti e tras túa, importante como argumento para a hipótese elaborada supra (apartado 3.4) como explicación do avance de POS neste tipo de secuencias.

A mesma obra de 1951 ofrece os exemplos máis antigos de atrás con POS. Trátase de tres

34 No exemplo Fprep emprégase cun antecedente [+humano]: "Chegou Fernando polo outro, e fixo o própeo [...]. Por diante del non pasaba ningún dos que botaban o viño".

35 Velaquí o exemplo: "Pra unha banda unha grande mesa de escribir, con librotes e papeis ós lados, no medio unha escribanía antiga. Á beira da mesa e contra a parede un grande sillón abacial, por riba del e sobre dun pano verde que cobre a parede un grande Cristo".

36 Canto ás características semánticas dos antecedentes, en tres casos son [-animados] e un exemplo máis é [+animado], aínda que [-humano]: trátase do mesmo animal, o lobo, que en (16).

37 A equivalencia entre tras ti e tras de ti pódese probar co exame do seguinte exemplo da tradución de A. Iglesia Alvariño: "Tras ti, tras de ti irei pra onde vaias, e estou disposto para ir contigo ó derradeiro viaxe". 
casos con posesivo de segunda persoa na mesma estrutura, e un máis de atrás nosa:

(17) Á noite, cando soño, algunhas veces, téñote xa nas maus; e, logo, voas coma un páxaro, e ieu vou atrás túa, atrás túa no herbal do Campo Marcio, atrás túa por riba do regueiro que corre (A. Iglesia Alvariño, Quinto Horacio Flacco: canciós, 1951; tradución de poesías do autor latino)

(18) ¡Coute si é que se atreve o desenfreno que campa polas rúas! Gabarano despois os que atrás nosa veñan vindo! (Id.)

Neste mesmo texto non se localiza exemplo ningún con atrás e Fprep ${ }^{38}$.

Continuando coa análise das formas dos grupos 1 e 2, na escrita da década dos 60 e 70 a variante innovadora testemúñase unicamente en combinación cos adverbios detrás e atrás:

(19) I eu corro detrás túa. Mais ti, de ponla en fror, de fonte en herba, fuxes (R. Carballo Calero, Salterio de Fingoy; 1961; poesía)

(20) CREGO PRIMEIRO Mais ¿veñen atrás vosa? (I. Millán González-Pardo, Morte da catedral; 1973; tradución dunha obra teatral de T.S.Elliott)
Dos anos 70 do século XX provén o seguinte exemplo, con lonxe en compañía do posesivo. Aínda que a edición da obra é de 1974, o poema en que ocorre a estrutura ten data propia: 1954:

(21) Viñen estar cos tesos belida - coor de lúa —/l que me leven lonxe túa que non sein a onde ir que for // perderme en cousa maior (U. Novoneyra, Os Eidos 2, 1974 [1954]; poesía).

A ocorrencia, única entre as obras deste autor no corpus TILG, parece favorecida pola rima e presenta como característica peculiar o feito de estar construída sobre unha forma das catalogadas coma do tipo 4 nas que, segundo veremos, o fenómeno penetra de xeito pouco significativo numericamente (cf. infra, apartado 4.2.3.3).

\subsubsection{Anos 80 do século XX: importante avan- ce cuantitativo nas formas 1 e 2, diversificación cualitativa da innovación cara aos grupos 3, 4 e 6}

4.2.3.1. Formas de documentación temperá: enriba e riba (tipo 1), diante, detrás e tras (tipo 2)

O cadro 5 achega unha visión do avance de POS con aquelas unidades en que se documentara a innovación de maneira máis temperá:

\begin{tabular}{|l|l|l|l|l|}
\hline Forma & Total Fprep TILG & Total POS TILG & Total Fprep. CORGA & Total POS CORGA \\
\hline Enriba & 346 & $20(5,7 \%)$ & 305 & $31(10,2 \%)$ \\
\hline Riba & 135 & $11(8,1 \%)$ & 162 & $13(7,4 \%)$ \\
\hline Diante & 513 & $133(20,5 \%)$ & 1049 & $267(20,2 \%)$ \\
\hline Detrás & 322 & $37(11,2 \%)$ & 613 & $129(17,3 \%)$ \\
\hline Tras & 405 & $18(4,2 \%)$ & 709 & $55(7,1 \%)$ \\
\hline Atrás & 67 & $16(20,4 \%)$ & 83 & $15(15,3 \%)$ \\
\hline
\end{tabular}

Cadro 5. Número total de exemplos de Fprep e POS en formas dos tipos 1 (enriba, riba) e 2 (diante, detrás, tras)

Comparando os datos de ambos os corpus, obsérvase que CORGA sempre testemuña un lixeiro ou moderado avance da innovación (agás no caso de riba, en que as cifras son practicamente equivalentes). Proponse interpretar este feito como síntoma do asentamento de POS naquelas frases preposicionais nucleadas a partir de elementos en que aparece de vello a variante innovadora.

Achéganse deseguido os cadros 6-17, en que se analiza a importancia porcentual da persoa gramatical no avance da innovación.

38 Revisadas as obras de A. Iglesia Alvariño presentes en TILG (anos 1930, 1933, 1947, 1950, 1951, 1960 e 1960), non se localiza exemplo ningún daqueles susceptibles de presentaren variación, polo que a alternancia entre POS e Fprep queda neste autor reducida ao mencionado texto de 1951. 


\begin{tabular}{|c|c|c|c|c|c|c|c|c|c|c|c|}
\hline \multicolumn{2}{|c|}{$1^{\text {a }}$ pers. } & \multicolumn{2}{|c|}{$2^{a}$ pers. } & \multicolumn{2}{|c|}{$3^{a}$ pers. } & \multicolumn{2}{|c|}{$4^{\mathrm{a}}$ pers. } & \multicolumn{2}{|c|}{$5^{\mathrm{a}}$ pers. } & \multicolumn{2}{|c|}{$6^{a}$ pers. } \\
\hline $\mathrm{FP}$ & Pos. & $\mathrm{FP}$ & Pos. & $\mathrm{FP}$ & Pos. & $\mathrm{FP}$ & Pos. & $\mathrm{FP}$ & Pos. & $\mathrm{FP}$ & POS \\
\hline $\begin{array}{c}73,7 \% \\
(14 / 19)\end{array}$ & $\begin{array}{l}26,3 \% \\
(5 / 19)\end{array}$ & $\begin{array}{c}55,6 \% \\
(5 / 9)\end{array}$ & $\begin{array}{c}44,4 \% \\
(4 / 9)\end{array}$ & $\begin{array}{c}97,1 \% \\
(207 / 212)\end{array}$ & $\begin{array}{c}2,9 \% \\
(5 / 212)\end{array}$ & $\begin{array}{c}70 \% \\
(14 / 20)\end{array}$ & $\begin{array}{c}30 \% \\
(6 / 20)\end{array}$ & $\begin{array}{c}(100 \%) \\
(4 / 4)\end{array}$ & $\begin{array}{c}0 \% \\
(0 / 4)\end{array}$ & $\begin{array}{c}100 \% \\
(51 / 51)\end{array}$ & $\begin{array}{c}0 \% \\
(0 / 51)\end{array}$ \\
\hline
\end{tabular}

Cadro 6: Enriba con FPrep e con POS en TILG (despois de 1982)

\begin{tabular}{|c|c|c|c|c|c|c|c|c|c|c|c|}
\hline \multicolumn{2}{|c|}{$\mathbf{1}^{\text {a }}$ pers. } & \multicolumn{2}{c|}{$\mathbf{2}^{\text {a }}$ pers. } & \multicolumn{2}{c|}{$\mathbf{3}^{\text {a }}$ pers. } & \multicolumn{2}{c|}{$\mathbf{4}^{\text {a }}$ pers. } & \multicolumn{2}{c|}{$\mathbf{5}^{\text {a pers. }}$} & \multicolumn{2}{c|}{$\mathbf{6}^{\text {a pers. }}$} \\
\hline FP & Pos. & FP & Pos. & FP & Pos. & FP & Pos. & FP & Pos. & FP & POS \\
\hline $72,9 \%$ & $27,1 \%$ & $\begin{array}{c}54,5 \% \\
(6 / 11)\end{array}$ & $\begin{array}{c}45,5 \% \\
(5 / 11)\end{array}$ & $\begin{array}{c}92,3 \% \\
(145 / 157)\end{array}$ & $\begin{array}{c}7,6 \% \\
(12 / 157)\end{array}$ & $\begin{array}{c}97,1 \% \\
(34 / 35)\end{array}$ & $\begin{array}{c}2,9 \% \\
(1 / 35)\end{array}$ & $\begin{array}{c}100 \% \\
(4 / 4)\end{array}$ & $\begin{array}{c}0 \% \\
(0 / 4)\end{array}$ & 50 & 0 \\
\hline
\end{tabular}

Cadro 7: Enriba con FPrep e con POS en CORGA

\begin{tabular}{|c|c|c|c|c|c|c|c|c|c|c|c|}
\hline \multicolumn{2}{|c|}{$1^{a}$ pers. } & \multicolumn{2}{|c|}{$2^{a}$ pers. } & \multicolumn{2}{|c|}{$3^{\text {a }}$ pers. } & \multicolumn{2}{|c|}{$4^{a}$ pers. } & \multicolumn{2}{|c|}{$5^{\mathrm{a}}$ pers. } & \multicolumn{2}{|c|}{$6^{\mathrm{a}}$ pers. } \\
\hline FP & Pos. & FP & Pos. & FP & Pos. & FP & Pos. & FP & Pos. & FP & POS \\
\hline $\begin{array}{c}73,6 \% \\
(20 / 26)\end{array}$ & $\begin{array}{l}23,7 \% \\
(6 / 26)\end{array}$ & $\begin{array}{c}90 \% \\
(9 / 10)\end{array}$ & $\begin{array}{c}10 \% \\
(1 / 10)\end{array}$ & $\begin{array}{c}98,9 \% \\
(98,9 \%)\end{array}$ & $\begin{array}{c}1,1 \% \\
(1,1 \%)\end{array}$ & $\begin{array}{l}87,5 \% \\
(21 / 24)\end{array}$ & $\begin{array}{l}12,5 \% \\
(3 / 24)\end{array}$ & $\begin{array}{c}100 \% \\
(1 / 1)\end{array}$ & $\begin{array}{c}0 \% \\
(1 / 1)\end{array}$ & $\begin{array}{l}\mathrm{Nc} \\
\text { loc }\end{array}$ & \\
\hline
\end{tabular}

Cadro 8. Riba con Fprep e con POS en TILG (despois de 1982)

\begin{tabular}{|c|c|c|c|c|c|c|c|c|c|c|c|}
\hline \multicolumn{2}{|c|}{$1^{\mathrm{a}}$ pers. } & \multicolumn{2}{|c|}{$2^{\mathrm{a}}$ pers. } & \multicolumn{2}{|c|}{$3^{a}$ pers. } & \multicolumn{2}{|c|}{$4^{a}$ pers. } & \multicolumn{2}{|c|}{$5^{\text {a }}$ pers. } & \multicolumn{2}{|c|}{$6^{a}$ pers. } \\
\hline FP & Pos. & FP & Pos. & FP & Pos. & FP & Pos. & FP & Pos. & FP & POS \\
\hline $\begin{array}{c}80 \% \\
(28 / 35)\end{array}$ & $\begin{array}{c}20 \% \\
(7 / 35)\end{array}$ & $\begin{array}{c}66,6 \% \\
(6 / 9)\end{array}$ & $\begin{array}{c}33,3 \% \\
(3 / 9)\end{array}$ & $\begin{array}{c}99,1 \% \\
(102 / 103)\end{array}$ & $\begin{array}{c}0,9 \% \\
(1 / 103)\end{array}$ & $\begin{array}{c}92,8 \% \\
(26 / 28)\end{array}$ & $\begin{array}{l}7,1 \% \\
(2 / 28)\end{array}$ & \multicolumn{4}{|c|}{ Non se localiza } \\
\hline
\end{tabular}

Cadro 9. Riba con Fprep e con POS en CORGA

\begin{tabular}{|c|c|c|c|c|c|c|c|c|c|c|c|}
\hline \multicolumn{2}{|c|}{$1^{\text {a }}$ pers. } & \multicolumn{2}{|c|}{$2^{a}$ pers. } & \multicolumn{2}{|c|}{$3^{a}$ pers. } & \multicolumn{2}{|c|}{$4^{a}$ pers. } & \multicolumn{2}{|c|}{$5^{\mathrm{a}}$ pers. } & \multicolumn{2}{|c|}{$6^{\text {a }}$ pers. } \\
\hline TRAD $^{39}$ & Pos. & TRAD & Pos. & TRAD & Pos. & TRAD & Pos. & TRAD & Pos. & TRAD & POS \\
\hline $\begin{array}{c}60,8 \% \\
(87+ \\
5 / 143)\end{array}$ & $\begin{array}{c}35,6 \% \\
(51 / 143)\end{array}$ & $\begin{array}{l}50 \% \\
(17+ \\
1 / 34)\end{array}$ & $\begin{array}{c}47,05 \% \\
(16 / 34)\end{array}$ & $\begin{array}{c}86,4 \% \\
(272+ \\
13 / 315)\end{array}$ & $\begin{array}{c}13,6 \% \\
(43 / 315)\end{array}$ & $\begin{array}{c}68 \% \\
(51 / 75)\end{array}$ & $\begin{array}{c}28 \% \\
(21 / 75)\end{array}$ & $\begin{array}{c}72 \% \% \\
(7 / 10)\end{array}$ & $\begin{array}{l}20 \% \\
(2 / 10)\end{array}$ & $\begin{array}{l}100 \% \\
(79+ \\
1 / 80)\end{array}$ & $0 \%$ \\
\hline
\end{tabular}

Cadro 10. Diante coas variantes tradicionais (Fprep ou pronome persoal) e con POS en TILG (a partir de 1982)

\begin{tabular}{|c|c|c|c|c|c|c|c|c|c|c|c|}
\hline \multicolumn{2}{|c|}{$\mathbf{1}^{\text {a }}$ pers. } & \multicolumn{2}{c|}{$\mathbf{2}^{\text {a }}$ pers. } & \multicolumn{2}{c|}{$\mathbf{3}^{\text {a }}$ pers. } & \multicolumn{2}{c|}{$\mathbf{4}^{\text {a }}$ pers. } & \multicolumn{2}{c|}{$\mathbf{5}^{\text {a }}$ pers. } & \multicolumn{2}{c|}{$\mathbf{6}^{\text {a pers. }}$} \\
\hline TRAD & Pos. & TRAD & Pos. & TRAD & Pos. & TRAD & Pos. & TRAD & Pos. & TRAD & POS \\
\hline $\begin{array}{c}60,2 \% \\
(183+\end{array}$ & $39,5 \%$ & $54,7 \%$ & $45,3 \%$ & 522 & $\begin{array}{c}11,3 \% \\
67\end{array}$ & $\begin{array}{c}65,4 \% \\
(89 / 136)\end{array}$ & $\begin{array}{c}34,6 \% \\
(47 / 136)\end{array}$ & $\begin{array}{c}46,7 \% \\
(7 / 15)\end{array}$ & $\begin{array}{c}53,3 \% \\
(8 / 15)\end{array}$ & $\begin{array}{c}(219 / \\
220)\end{array}$ & $\begin{array}{c}0,5 \% \\
(1 / 220)\end{array}$ \\
\hline $1 / 304)$ & $(120 / 304)$ & $(29 / 53)$ & $(24 / 53)$ & 522 & & & & & & &
\end{tabular}

Cadro 11. Diante coas variantes tradicionais (Fprep ou pronome persoal) en CORGA

\begin{tabular}{|c|c|c|c|c|c|c|c|c|c|c|c|}
\hline \multicolumn{2}{|c|}{$1^{a}$ pers. } & \multicolumn{2}{|c|}{$2^{\text {a }}$ pers. } & \multicolumn{2}{|c|}{$3^{a}$ pers. } & \multicolumn{2}{|c|}{$4^{\text {a }}$ pers. } & \multicolumn{2}{|c|}{$5^{\text {a }}$ pers. } & \multicolumn{2}{|c|}{$6^{\mathrm{a}}$ pers. } \\
\hline FP & Pos. & FP & Pos. & FP & Pos. & FP & Pos. & FP & Pos. & FP & POS \\
\hline $\begin{array}{c}68,2 \% \\
(30 / 44)\end{array}$ & $\begin{array}{c}31,8 \% \\
(14 / 44)\end{array}$ & $\begin{array}{l}75 \% \\
(6 / 8)\end{array}$ & $\begin{array}{l}25 \% \\
(2 / 8)\end{array}$ & $\begin{array}{c}96,3 \% \\
(183 / 190)\end{array}$ & $\begin{array}{c}3,6 \% \\
(7 / 190)\end{array}$ & $\begin{array}{c}73,6 \% \\
(39 / 53)\end{array}$ & $\begin{array}{c}26,4 \% \\
(14 / 53)\end{array}$ & $\begin{array}{l}100 \% \\
(2 / 2)\end{array}$ & $\begin{array}{c}0 \% \\
(0 / 2)\end{array}$ & $\begin{array}{c}100 \% \\
(62 / 62)\end{array}$ & $\begin{array}{c}0 \% \\
(0 / 62)\end{array}$ \\
\hline
\end{tabular}

Cadro 12. Detrás con Fprep e con POS en TILG (despois de 1982)

39 Como primeiro elemento da suma aparece o número de ocorrencias con preposición de; o segundo elemento alude a estruturas sen preposición de. De haber un único número, este corresponde ao primeiro tipo. 


\begin{tabular}{|c|c|c|c|c|c|c|c|c|c|c|c|}
\hline \multicolumn{2}{|c|}{$\mathbf{1}^{\text {a }}$ pers. } & \multicolumn{2}{c|}{$\mathbf{2}^{\text {a }}$ pers. } & \multicolumn{2}{c|}{$3^{\text {a }}$ pers. } & \multicolumn{2}{c|}{$\mathbf{4}^{\text {a }}$ pers. } & \multicolumn{2}{c|}{$\mathbf{5}^{\text {a }}$ pers. } & \multicolumn{2}{c|}{$\mathbf{6}^{\text {a pers. }}$} \\
\hline FP & Pos. & FP & Pos. & FP & Pos. & FP & Pos. & FP & Pos. & FP & POS \\
\hline $\begin{array}{c}53,7 \% \\
(58 / 108)\end{array}$ & $\begin{array}{c}46,3 \% \\
(50 / 108)\end{array}$ & $\begin{array}{c}50 \% \\
(12 / 24)\end{array}$ & $\begin{array}{c}50 \% \\
(12 / 24)\end{array}$ & $\begin{array}{c}90,1 \% \\
(384 / 426)\end{array}$ & $\begin{array}{c}9,8 \% \\
(42 / 426)\end{array}$ & $\begin{array}{c}56,6 \% \\
(30 / 53)\end{array}$ & $\begin{array}{c}43,4 \% \\
(23 / 53)\end{array}$ & $\begin{array}{c}50 \% \\
(1 / 2)\end{array}$ & $\begin{array}{c}50 \% \\
(1 / 2)\end{array}$ & $\begin{array}{c}99,2 \% \\
(128 / 129)\end{array}$ & $\begin{array}{c}0,8 \% \\
(1 / 129)\end{array}$ \\
\hline
\end{tabular}

Cadro 13. Detrás con Fprep e con POS en CORGA

\begin{tabular}{|c|c|c|c|c|c|c|c|c|c|c|c|}
\hline \multicolumn{2}{|c|}{$\mathbf{1}^{\text {a }}$ pers. } & \multicolumn{2}{c|}{$\mathbf{2}^{\text {a }}$ pers. } & \multicolumn{2}{c|}{$\mathbf{3}^{\text {a }}$ pers. } & \multicolumn{2}{c|}{$\mathbf{4}^{\text {a }}$ pers. } & \multicolumn{2}{c|}{$\mathbf{5}^{\text {a }}$ pers. } & \multicolumn{2}{c|}{$\mathbf{6}^{\text {a pers. }}$} \\
\hline TRAD & Pos. & TRAD & Pos. & TRAD & Pos. & TRAD & Pos. & TRAD & Pos. & TRAD & POS \\
\hline \multirow{2}{*}{$86,3 \%$} & $13,7 \%$ & $66,6 \%$ & $33,3 \%$ & $\begin{array}{c}98,8 \% \\
(213+\end{array}$ & $\begin{array}{c}1,2 \% \\
(3 / 260)\end{array}$ & $\begin{array}{c}82,3 \% \\
(13+\end{array}$ & $\begin{array}{c}17,7 \% \\
(3 / 17)\end{array}$ & $\begin{array}{c}66,6 \% \\
(4 / 6)\end{array}$ & $\begin{array}{c}33,3 \% \\
(2 / 6)\end{array}$ & $\begin{array}{c}98,8 \% \\
(61+23 / 85)\end{array}$ & $\begin{array}{c}1,2 \% \\
(1 / 85)\end{array}$ \\
$(31+7 / 44)$ & $(6 / 44)$ & $(7+1 / 12)$ & $(4 / 12)$ & $44 / 260)$ & $(7+6 \%)$ & & & & & &
\end{tabular}

Cadro 14. Tras coas variantes tradicionais (Fprep ou pronome persoal) e con POS en TILG (a partir de 1982)

\begin{tabular}{|c|c|c|c|c|c|c|c|c|c|c|c|}
\hline \multicolumn{2}{|c|}{$\mathbf{1}^{\text {a }}$ pers. } & \multicolumn{2}{c|}{$\mathbf{2}^{\text {a }}$ pers. } & \multicolumn{2}{c|}{$\mathbf{3}^{\text {a }}$ pers. } & \multicolumn{2}{c|}{$\mathbf{4}^{\text {a }}$ pers. } & \multicolumn{2}{c|}{$\mathbf{5}^{\text {a }}$ pers. } & \multicolumn{2}{c|}{$\mathbf{6}^{\text {a }}$ pers. } \\
\hline TRAD & Pos. & TRAD & Pos. & TRAD & Pos. & TRAD & Pos. & TRAD & Pos. & TRAD & POS \\
\hline $75,8 \%$ & $24,2 \%$ & $57,1 \%$ & $42,9 \%$ & $\begin{array}{c}73,8 \% \\
(373+\end{array}$ & $\begin{array}{c}26,2 \% \\
(23 / 533)\end{array}$ & $\begin{array}{c}66,6 \% \\
(17+\end{array}$ & $\begin{array}{c}33,3 \% \\
(10 / 30)\end{array}$ & $\begin{array}{c}100 \% \\
(2 / 2)\end{array}$ & $\begin{array}{c}0 \% \\
(0 / 2)\end{array}$ & $\begin{array}{c}99,1 \% \\
(68+\end{array}$ & $\left.\begin{array}{c}0,1 \% \\
(1 / 123)\end{array}\right)$ \\
$1 / 62)$ & $(15 / 62)$ & $(8 / 12)$ & $(6 / 12)$ & $137 / 533)$ & & & & & &
\end{tabular}

Cadro 15. Tras coas variantes tradicionais (Fprep ou pronome persoal) e con POS en CORGA

\begin{tabular}{|c|c|c|c|c|c|c|c|c|c|c|c|}
\hline \multicolumn{2}{|c|}{$1^{\mathrm{a}}$ pers. } & \multicolumn{2}{|c|}{$2^{a}$ pers. } & \multicolumn{2}{|c|}{$3^{a}$ pers. } & \multicolumn{2}{|c|}{$4^{a}$ pers. } & \multicolumn{2}{|c|}{$5^{\mathrm{a}}$ pers. } & \multicolumn{2}{|c|}{$6^{a}$ pers. } \\
\hline TRAD & Pos. & TRAD & Pos. & TRAD & Pos. & TRAD & Pos. & TRAD & Pos. & TRAD & POS \\
\hline $\begin{array}{c}63,3 \% \\
(12+ \\
2 / 22)\end{array}$ & $\begin{array}{l}36,7 \% \\
(8 / 22)\end{array}$ & $\begin{array}{l}100 \% \\
(2 / 2)\end{array}$ & $\begin{array}{c}0 \% \\
(0 / 2)\end{array}$ & $\begin{array}{c}93,6 \% \\
(44 / 47)\end{array}$ & $\begin{array}{c}6,4 \% \\
(3 / 47)\end{array}$ & $\begin{array}{c}63,6 \% \\
(4+ \\
3 / 11)\end{array}$ & $\begin{array}{l}36,4 \% \\
(4 / 11)\end{array}$ & $\begin{array}{c}0 \% \\
(0 / 1)\end{array}$ & $\begin{array}{c}100 \% \\
(1 / 1)\end{array}$ & \multicolumn{2}{|c|}{ Non se documenta } \\
\hline
\end{tabular}

Cadro 16. Atrás coas variantes tradicionais (Fprep ou pronome persoal) e con POS en TILG (a partir de 1982)

\begin{tabular}{|c|c|c|c|c|c|c|c|c|c|c|c|}
\hline \multicolumn{2}{|c|}{$1^{a}$ pers. } & \multicolumn{2}{|c|}{$2^{\mathrm{a}}$ pers. } & \multicolumn{2}{|c|}{$3^{\text {a }}$ pers. } & \multicolumn{2}{|c|}{$4^{\text {a }}$ pers. } & \multicolumn{2}{|c|}{$5^{\text {a }}$ pers. } & \multicolumn{2}{|c|}{$6^{\mathrm{a}}$ pers. } \\
\hline TRAD & Pos. & TRAD & Pos. & TRAD & Pos. & TRAD & Pos. & TRAD & Pos. & TRAD & POS \\
\hline $\begin{array}{l}77,2 \% \\
(17 / 22)\end{array}$ & $\begin{array}{l}22,7 \% \\
(5 / 22)\end{array}$ & $\begin{array}{c}87,5 \% \\
(7 / 8)\end{array}$ & $\begin{array}{c}12,5 \% \\
(1 / 8)\end{array}$ & $\begin{array}{c}96 \% \\
(48 / 50)\end{array}$ & $\begin{array}{c}4 \% \\
(2 / 50)\end{array}$ & $\begin{array}{l}36,4 \% \\
(4 / 11)\end{array}$ & $\begin{array}{l}63,6 \% \\
(7 / 11)\end{array}$ & \multicolumn{4}{|c|}{ Non hai exemplos } \\
\hline
\end{tabular}

Cadro 17. Atrás coas variantes tradicionais (Fprep ou pronome persoal) e con POS en CORGA

Un dato de interese que é posible deducir dos cadros refírese á comparación entre as persoas relacionadas co coloquio fronte a terceira e sexta persoas: naquelas o avance da innovación é maior cuantitativamente, nestas moito menor, o cal é esperable por causa da menor capacidade de recuperación do antecedente que presenta o paradigma dos posesivos nas persoas non ligadas ao coloquio. A modo de exemplo e tomando como base os datos achegados polo corpus CORGA, preséntase no gráfico 1 unha comparación entre primeira e terceira persoas:

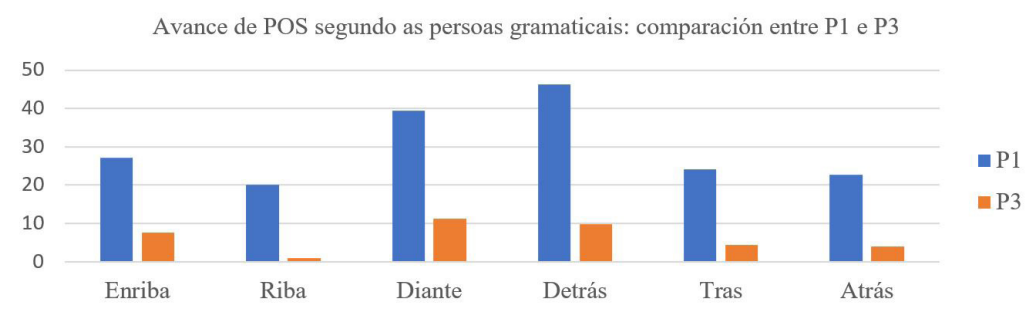

Gráfico 1. Avance de POS segundo as persoas gramaticais: comparación entre P1 e P3 
O gráfico permite tamén extraer a evidencia de que son as formas diante e detrás aquelas en que a ocorrencia de POS progresa con maior rotundidade. En efecto, con estes adverbios a primeira persoa está preto de alcanzar o $50 \%$ do total de exemplos.

Deseguido analízanse algunhas limitacións, de diverso tipo, que poden contribuír á explicación da menor rendibilidade de súa fronte ao resto das persoas do paradigma dos posesivos. En primeiro lugar, a posibilidade de que se trate dun posesivo de cortesía de segunda persoa só aparece corroborada por exemplos illados:

(22) É vostede? Levamos vinte e catro horas detrás súa e vostede sen dar sinais de vida (M. Portas, Un dedo manchado de tinta; 2011; narrativa)

En segundo termo, a detección de exemplos en que súa actúe como posesivo de sexta persoa é tamén residual e limítase aos seguintes casos, o primeiro deles común a ambos os corpus e o segundo e o terceiro testemuñado por CORGA:

(23) De termos en conta, ademais, que eses veciños tiñan detrás súa unha longa tradición de explotación neste mesmo século, entenderemos por que a primeira reacción popular foi negativa (O. Sotelo Blanco, A concentración parcelaria. 1994; ensaio)

(24) Coma se non puideran meterme na cadea, e eles mesmos fosen enfrontarse ao espello dos seus actos. Porque saben que iso diante súa é a extensión do meu amor, (D. Pérez Iglesias, 1993, Estación Término / Paisaxe para despois; relato curto)

(25) Don Javier e a súa dona esforzabanse en segui-la liturxia. Contestaban sen falla ó ritual latino. Despois da bendición deixaron tras súa o cheiro santeiro do incenso e da cera das candeas (L. M. García Mañá, O lume do Santo Antón; 1997; narrativa)

En terceiro lugar, unha restrición moi evidente no avance da innovación en terceira e sexta persoas é o feito de esta se producir case unicamente no caso de que a relación anafórica permita recuperar rerferentes [+humanos] ou [+animados]. Entidades doutro tipo deben entenderse como personificadas, o que ocorre en (26):
(26) Foi entonces cando vimos aquilo. Semellaba un punto lonxano, vermello e candente, que cruzaba o ceo, veloz, deixando detrás súa un ronsel de lume (L. Fernández Marcos, Galaxia lonxana; 1995; narración xuvenil)

Só se localiza unha excepción. En (27) POS emprégase na frase preposicional mais o seu antecedente non semella estar personificado:

(27) Non só vai seguir adiante a reforma do Estatuto de Euskadi, con novos escenarios, senón que, detrás súa, van vir máis (Alfonso Eiré, A Nosa Terra, 2005; xornal)

Existen indicios evidentes, daquela, de que na competencia entre Fprep e POS a innovación avanza vinculada ao grao de humanización do referente que se recupera a través do procedemento anafórico.

\subsubsection{Outros adverbios dos tipos 1 e 2: de-} rriba, encima, baixo e embaixo

Canto ao resto das unidades que están tamén presentes nos grupos 1 e 2 do cadro 3, e aínda que a localización de exemplos non permite unha interpretación porcentual, si é posible sinalar a penetración da innovación en todas as formas, así como o mantemento das tendencias sinaladas no apartado anterior canto ao desigual avance por persoas gramaticais. Deseguido preséntanse os datos que avalan ambas as afirmacións.

O TILG só achega un exemplo estruturalmente innovador con encima: encima súa (2000; o mesmo corpus presenta 43 documentacións da estrutura frástica en terceira persoa). O CORGA, pola súa parte, permite constatar a propagación da innovación a debaixo nas seguintes proporcións, datas e persoas: debaixo túa (2010: 3 exemplos de debaixo de ti), e debaixo nosa (2 en 1998, unha en 2011; debaixo de nós, cinco exemplos). Debaixo súa ocorre en dúas ocasións, unha de terceira persoa (fronte a 41 casos de Fprep) e outra de sexta (11 exemplos de Fprep). Canto a baixo e embaixo, ambos as unidades achegan un número reducido e recente de exemplos innovadores, como se pode ver no seguinte cadro:

\begin{tabular}{|l|l|l|l|l|}
\hline \multicolumn{2}{|c|}{ Documentacións de baixo + POS } & \multicolumn{2}{c|}{ Documentacións de embaixo + POS } \\
\hline TILG & $\begin{array}{l}\text { Baixo túa, 1, 1989 } \\
\text { (baixo de ti, 1; baixo ti, 1) }\end{array}$ & $\begin{array}{l}\text { Baixo súa, 1, 1987 } \\
\text { (Fprep, 27) }\end{array}$ & $\begin{array}{l}\text { Embaixo túa, 1, 2003 } \\
\text { (sen documentación de Fprep) }\end{array}$ & $\begin{array}{l}\text { Embaixo súa, 1994 } \\
\text { (Fprep, 5) }\end{array}$ \\
\hline CORGA & $\begin{array}{l}\text { Baixo miña }, 1,1988 \\
\text { (baixo de min, 4) }\end{array}$ & $\begin{array}{l}\text { Embaixo túa, 1, 2012 } \\
\text { (embaixo de ti, 2) }\end{array}$ \\
\hline
\end{tabular}

Cadro 18: Baixo e embaixo en combinación con POS 
Pódese afirmar, daquela, que aquelas unidades dos tipos 1 e 2 en que non se localizan exemplos temperáns da innovación si coñecen unha penetración de POS na súa estrutura, mais esta é recente, sempre posterior aos anos 80 do século XX.

\subsubsection{Formas dos tipos 3 (dentrolfóra) e 4 (lonxe, preto/perto, cerca, cabo)}

Ambos as categorías testemuñan en escasa medida e tardiamente a innovación. Fóra é o único adverbio que non se detecta xerando estruturas con $\mathrm{POS}^{40}$ e dentro presenta escasas ocorrencias, tanto no TILG como no CORGA, unicamente a partir dos anos 80 do século $\mathrm{XX}^{41}$. Por outro lado, as formas do tipo 4 debutan algo antes pero non avanzan numéricamente na súa competencia con POS: lonxe túa documéntase, como se indicou anteriormente (exemplo 21), en 1979 (nove casos no mesmo período de lonxe de ti). O CORGA ofrécenos algún exemplos máis, todos eles xa próximos ou plenamente inseridos no século XXI: preto nosa (dous casos, en 1994 e 2009; preto de nós aparece no mesmo período en 34 ocasións); perto miña (un exemplo, 2001; perto de min, nove casos); cerca miña (un caso en 2009, tres exemplos de Fprep tamén no mesmo período); cerca túa (un exemplo en 1994; unha ocorrencia de cerca de ti).
Por último, ambos os corpus permiten detectar a progresión de POS cara ás estruturas relacionadas coa preposición cabo. Localízanse dous exemplos en TILG (cabo súa, 2000, e cabo nosa, 1989) e outros dous casos de terceira persoa en CORGA, ambos de 2000 e un deles coincidente co documentado en TILG. Nesta unidade, porén, a innovación é residual porcentualmente, dada a a importante presenza da variante frástica: a modo de exemplo, sinálase que no último destes corpus aparecen 231 casos de cabo del/ela/si.

Pódese concluír, daquela, que a penetración da innovación nos adverbios dos tipos 3 e 4 é reducida, ou inexistente (para a forma fóra), e sempre, agás o mencionado exemplo de lonxe, posterior aos anos 80 do século XX.

\subsubsection{Formas do tipo 6 (xunto/xunta)}

A análise da variación xerada por estas dúas unidades, das cales a segunda deriva da primeira por contracción de xunto $a$, ofrece unha especial complexidade, pola existencia xa non de dúas ou tres, senón de catro posibilidades estruturais: xunto/xunta + pronome persoal, xunto/xunta + prep. $a+$ pronome persoal, xunto/xunta + prep. de + pronome persoal e, finalmente, a variante innovadora xunto/xunta + POS. Nas táboas que seguen ofrecemos o número total de ocorrencias para ambas as formas e nas distintas variantes:

\begin{tabular}{|l|l|l|c|}
\hline \multirow{2}{*}{ Corpus } & \multicolumn{1}{|c|}{ Forma } & Número total & $\begin{array}{c}\text { Data máis antiga de } \\
\text { documentación }\end{array}$ \\
\hline \multirow{3}{*}{ TILG } & Xunto + pronome persoal & 16 ocorrencias & 1864 \\
\cline { 2 - 4 } & Xunto $+a+$ pronome persoal & 80 ocorrencias & 1864 \\
\cline { 2 - 4 } & Xunto + de + pronome persoal & 209 ocorrencias & 1862 \\
\cline { 2 - 4 } & Xunto + posesivo & 4 ocorrencias ${ }^{42}$ & 1982 \\
\hline \multirow{3}{*}{ CORGA } & Xunto + pronome persoal & 4 ocorrencias & 1995 \\
\cline { 2 - 4 } & Xunto $+a+$ pronome persoal & 222 ocorrencias & 1976 \\
\cline { 2 - 4 } & Xunto + de + pronome persoal & 80 ocorrencias & 1976 \\
\cline { 2 - 4 } & Xunto + posesivo & 5 ocorrencias & 43 \\
\hline
\end{tabular}

Cadro 19. Exame da variación con xunto nos corpus TILG e CORGA

40 A aparición deste elemento en combinación con Fprep é significativa numericamente: así, en TILG fóra de min aparece en 50 ocasións, fóra de ti en 13, fóra del, dela, deles, delas, de si nun total de 411 casos, fóra de nós en 22 e fóra de vós nun exemplo. En CORGA os números son como seguen: fóra de min tres casos, fóra de ti catro, fóra del, dela, deles, delas, de si sete e fóra de nós un exemplo. A ausencia de POS en combinación coa unidade non se debe, daquela, á ocorrencia dun número reducido de exemplos posibles.

${ }^{41}$ Localizamos os seguintes exemplos nos corpus (o total refírese á suma dos casos de ambas as variantes, tradicional e innovadora): en TILG dentro miña, 4/179; dentro túa, 3/31; dentro súa, 13/520; dentro nosa, 2/66; dentro vosa, 0/3. En CORGA, dentro miña, 4/25; dentro túa, 1/9; dentro súa, 1/55. Todos os exemplos con posesivo son da década dos 80, agás dous dos anos 90. Neste mesmo período o CORGA documenta tres casos de dentro meu e un de dentro teu, todos eles en textos do autor Martínez Oca.

42 Dous casos de xunto túa (o máis antigo, de 1982) e un caso de xunto súa (2000).

43 Dous casos de xunto miña (o máis antigo, 1981); unha ocorrencia de xunto túa (2000) e outra de xunto súa (2000). 


\begin{tabular}{|l|l|l|c|}
\hline \multirow{2}{*}{ Corpus } & \multicolumn{1}{|c|}{ Forma } & Número total & $\begin{array}{c}\text { Data máis antiga de } \\
\text { documentación }\end{array}$ \\
\hline \multirow{4}{*}{ TILG } & Xunta + pronome persoal & 161 ocorrencias & 1810 \\
\cline { 2 - 4 } & Xunta $+a+$ pronome persoal & 5 ocorrencias & 1974 \\
\cline { 2 - 4 } & Xunta + de + pronome persoal & 33 ocorrencias & 1863 \\
\cline { 2 - 4 } & Xunta + posesivo & 6 ocorrencias ${ }^{44}$ & 1982 \\
\hline \multirow{4}{*}{ CORGA } & Xunta + pronome persoal & 58 ocorrencias & 1982 \\
\cline { 2 - 4 } & Xunta $+a+$ pronome persoal & 1 ocorrencia & 2006 \\
\cline { 2 - 4 } & Xunta + de + pronome persoal & 28 ocorrencias & 1984 \\
\cline { 2 - 4 } & Xunta + posesivo & 4 ocorrencias & \\
& & & 1993 \\
\hline
\end{tabular}

Cadro 20. Exame da variación con xunta nos corpus TILG e CORGA

Segundo se pode observar, POS é sempre a alternativa estrutural máis tardía nunha situación de variación que vén de antigo, caracterizada polo avance das posibilidades que inclúen preposición (sobre todo $a$, para xunto, e de, para xunta). Ás tres opcións consolidadas incorpórase nos anos 80 , de maneira pouco significativa numericamente, a innovación POS, que se mantén como alternativa minoritaria ao longo do tempo.

\section{Aparición de estruturas de base nominal non concordadas con locucións adverbiais nucleadas por redor, carón, lado e rente (ti- pos 5 e 6)}

\subsection{Unha alternancia tradicional entre Fprep e POS (tipos 5, 6): a innovación consiste no emprego do feminino}

A natureza substantiva do elemento nuclear das locucións adverbiais que estudamos neste apartado xustifica que a localización de exemplos con posesivo concordado sexa temperá coas unidades deste tipo. En efecto, no corpus TILG ao/a redor e ao/a carón documéntase con modificación posesiva desde as décadas finais do XIX, mentres que ao/de lado ocorre con posesivo en masculino a partir de 1951. $\mathrm{O}$ adverbio arredor, grafado ocasionalmente a redor, aparece con posesivo en masculino desde 1880. Nada hai de excepcional nestas construcións, en que a presenza do posesivo se debe, segundo se vén de sinalar, á posibilidade de que este concorde a respecto dun elemento nuclear orixinalmente masculino ${ }^{46}$.

Cando se produce, daquela, a innovación sintáctica nestas locucións adverbiais? Consideramos que esta ten lugar cando o posesivo, sempre en posposición, abandona a súa concordancia orixinaria para aceptar a forma en feminino. As primeiras documentacións do fenómeno prodúcense a mediados do século $\mathrm{XX}$ e nas locucións ligadas ao substantivo redor:

(28) E no espazo qu'iba e viña redor miña sin fuxir // pois se un intre se alonxaba xa tornaba a rexurdir (X. San Luís Romero, Versos escritos en Buenos Aires e outros poemas, 1956; poesía)

(29) O Rei está na Francia, baralloando en Anjou; arredor súa axéxanno os famentos dos fillos (I. Millán González-Pardo, Morte na catedral, 1973; tradución dunha obra de teatro de T.S. Elliott)

44 Cinco casos de xunta miña (comezando en 1982) e un de xunta túa (1996).

45 Todas elas son de primeira persoa.

46 Ás locucións mencionadas, en que o posesivo en masculino non se considera innovador pola concordancia a respecto do elemento substantivo da locución, pódese engadir tamén aquelas xeradas polo substantivo fronte. Álvarez Blanco e Xove (2002: 615) describen unicamente as posibilidades en fronte de e fronte a e non mencionan se é posible ou non substituír, na primeira delas, Fprep por POS; porén, os corpus TILG e CORGA permiten documentar exemplos como os que seguen: "O cociñeiro Valichó, aquel bravo e groso individuo que sempre tan ben se comportou comigo nos longos días de prisión que fomos obrigados a compartir, falábame plantado, coas pernas moi abertas, fronte miña" (X. L. Méndez Ferrín, Bretaña, Esmeraldina, 1987; novela); "Algúns cabaleiros facían xesto de deterse fronte nosa pero non era máis que un xesto, e proseguían” (A. Rodríguez López, As reliquias, 1991; novela); "Oxalá todo o mundo puidese atopar cando menos unha vez na súa vida un tesouro coma o que eu teño agora en fronte miña (P. Feijóo, Os fillos do mar, 2012; novela). As secuencias testemuñan unha importante facilidade para a penetración do posesivo en estruturas adverbiais. 
O emprego de POS non concordado esténdese nos anos 90 cara á complementación das formas derredor (1993), alao carón (1991) e al ao lado (1991), en tanto que xa no inicio do novo século (2003) se documenta a rente mi$\tilde{n} a$. Ofrecemos deseguido un exemplo de cada unha destas documentacións:

(30) Derredor miña todo se desmorona mentres eu vivo noutro tempo, contigo, neste cuarto (X. Borrazás, Contos malvados. O poeta el, 1998; ficción)

(31) Só quero terte a carón miña para falarche (F. Fernández Naval, Tempo de crepúsculo, 1993; ficción)

(32) Pois (...) ó outro día caeu de lado miña, e entonces mireille a chaqueta (M. Gondar Portasany, Contos de mortos e outros relatos; 1991; escrita de divulgación)

Canto á proporción entre formas masculinas (concordadas) e a innovación que supón renunciar á concordancia do posesivo nas unidades analizadas, esta aparece reflectida no gráfico 2, que permite observar o desigual avance do posesivo non concordado coas diferentes locucións adverbiais. Con algunhas destas unidades, a progresión da ausencia de concordancia parece moi significativa.

\subsection{A extensión da innovación a outras uni- dades e outros ámbitos semánticos: emprego da variante non concordada coas locucións nucleadas por través e favor}

A utilización da forma feminina do posesivo rexístrase tamén en estruturas que teñen como elemento nuclear a forma través. O DRAG fixa como locucións correctas do través e ao través, con preferencia da primeira e xénero explicitamente marcado por medio do artigo. Ambas vincúlanse aos significados materiais ou físicos da estrutura, sintetizados na definición que achega o dicionario: "De maneira atravesada ou oblicua".

Porén, nos corpus analizados a través aparece abundantemente co significado abstracto de "mediante", case sempre nas persoas terceira e sexta e construído como é esperable tradicionalmente, con $d e+$ pronome persoal ${ }^{47}$. Así mesmo, POS penetra na estrutura nas persoas do coloquio, en exemplos como os que seguen:

(33) Penso que o meu pai (...) por medio da palabra, soubo el manterse vencellado ó mundo novo que petaba nas portas a través miña (A. Conde, Memoria de Noa; 1985; novela)

(34) Serás libre e eu sereino a través túa (A. Rodríguez López, As reliquias, 1991; novela)

(35) Sentei a carón del, pero a expresión da súa cara non se alterou, como se non me vira, ou máis ben como se mirase a través miña, sen embargo sabía máis do que aparentaba (R. Caride Ogando, Soños eléctricos; 1992)

A independencia a respecto dos valores de natureza espacial que caracteriza a través como núcleo da innovación é un elemento que a locución comparte coa que se estudará deseguido, (en)/(a) favor (de), estrutura que tamén admite o POS non concordado na súa construción. Fenómeno datado tamén no último terzo do século XX, permite testemuñar o avance

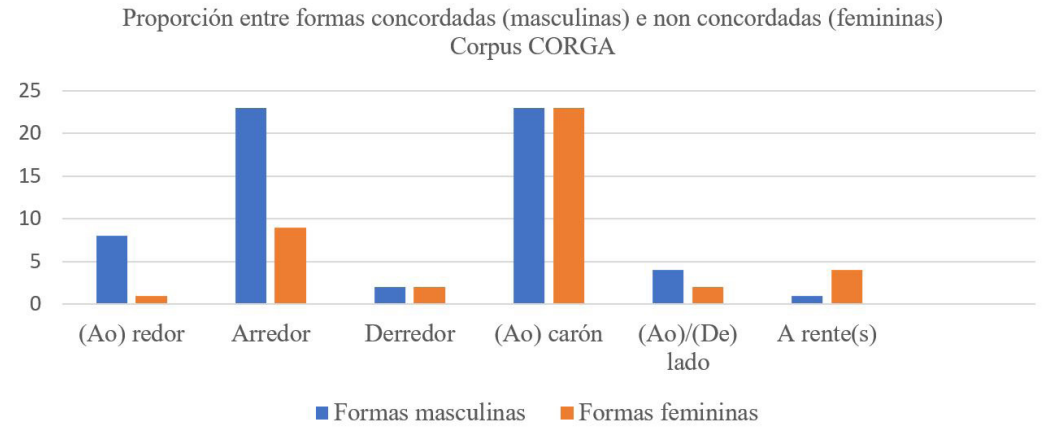

Gráfico 2. Proporción entre formas concordadas (masculinas) e non concordadas (femininas) coas locucións adverbiais nucleadas por redor, carón lado e rente(s). Corpus CORGA

47 O TILG rexistra 58 casos de a través del/dela e 39 de a través deles/delas. A ocorrencia da estrutura nas persoas ligadas ao coloquio é notablemente máis exigua: seis a través de min, un a través de ti, tres a través de nós e un a través de vós. Canto ao CORGA, a situación é similar: 115 a través del/dela, 46 a través deles/delas, seis a través de min e un a través de ti. 
da innovación cara a contornos cada vez máis independentes dos orixinais, dada a carencia de valores espaciais da estrutura. A opción en que aparece POS rexístrase por primeira vez en 1973:

(36) Ou Señor Arcebispo, ou Tomás Arcebispo, amerceádevos de nós, perdoádenos, rogade por nós pra que nós poidamos pregar en favor vosa, dendes do abismo da vergoña nosa (I. Millán González-Pardo, Morte na catedral, 1973; tradución dunha obra teatral de T. S. Elliott)

$\mathrm{O}$ corpus CORGA achega un caso de en favor nosa de 1991 e outro de en favor miña de 1989, a carón do seguinte exemplo xa do século XXI:

(37) Veloso Janeiro ollou para don Servando, como esperando que reaccionase e tomase parte dunha vez en favor súa (Francisco Castro, Spam, 2006; novela).

En Silva Domínguez (1995: 12) menciónase a relación de antonimia existente entre en contra de e a/en favor de como explicación da súa proximidade construtiva. Se ben a innovación carece de valor porcentual (só en CORGA rexístranse 215 exemplos de en/a seu favor e 14 de en/a favor del/dela), si testemuña o avance da ruptura da concordancia cara a estruturas diferentes das que posúen un valor locativo. A temperá cronoloxía de (36), anterior á eclosión dos anos 80 do século XX, é tamén un aspecto importante na descrición do fenómeno.

Como conclusión, a innovación consistente na suspensión de concordancia en locucións adverbiais con valor locativo documéntase de maneira temperá nos corpus estudados (anos 50 do século $\mathrm{XX}$ ) e coñece un significativo avance a partir dos anos 80 desta centuria. Alén da progresión cuantitativa, destaca tamén a supresión da limitación cualitativa asociada a valores espaciais: estruturas carentes destes significados incorpóranse tamén á innovación, algunhas xa nos anos 70 .

\section{Análise dos corpus CORILGA e ESLORA}

\subsection{CORILGA}

Os exemplos achegados por CORILGA son poucos numericamente, aínda que o máis importante é o feito de que estes corroboran os principais resultados obtidos no apartado anterior. A ocorrencia máis antiga de posesivo en estruturas locativas é relativamente recente: trátase dun caso de enriba túa producido por un varón con estudos primarios no ano 1995:

(38) Vas ir pa unha empresa traballar [...] Inda ben non che dan un saco de cemento e xa estás tu por debaixo do saco en vez de estar o saco por debaixo | po::r enriba túa.

Dous exemplos máis con enriba (miña e túa) documéntanse en boca de mulleres, unha delas de aproximadamente 30 anos e con estudos universitarios, outra menor de 20 anos e cursando Secundaria, ambos na segunda década do século XXI. Lembremos que, de acordo coa análise proposta no apartado anterior, é este adverbio un dos que con maior precocidade comeza a admitir o posesivo, xa nos anos 30 da centuria anterior. Por último, un varón de 71 anos e con formación universitaria achega un exemplo de xunto súa. Estes achados parecen coherentes a respecto dos obtidos no exame dos dous corpus maiores: a innovación documéntase de maneira máis temperá con enriba e só de maneira máis tardía con xunto.

\subsection{ESLORA}

O corpus introdúcese na análise coa finalidade de responder á cuestión de en que medida o español de Galicia partilla a innovación sintáctica que estudamos. A partir da tradución do anteriormente reproducido cadro 3 (cf. supra, apartado 4.1), buscáronse as seguintes formas: encima, debajo, abajo, delante, detrás, atrás, tras, dentro, fuera, lejos, cerca, alrededor e junto. Deseguido explícanse as súas posibilidades de complementación mediante Fprep e POS.

O primeiro aspecto que destacaremos é a ausencia de formas de posesivo en masculino, aspecto comentado anteriormente (cf. supra, apartado 1.2.4) e que establece unha diferenza notable a respecto doutras áreas lingüísticas hispanofalantes, peninsulares ou non. Canto ao feminino, localízanse no corpus un total de 13 exemplos innovadores, que permiten documentar a presenza do posesivo naqueles adverbios en que o galego a testemuña de maneira máis antiga e tamén máis frecuente. Trátase das equivalencias españolas dos tipos 1 e 2 do cadro 3: encima, delante, detrás e tras, en exemplos coma os que seguen:

(39) Yo al $<$ pausa/ $>$ a los $<$ pausa/ $>$ a los del tercero $<$ pausa/ $>$ los que están encima mía sí pero los del otro lado no sé <pausa/> quiénes son $<$ pausa $/>$ no los conozco (muller, 45 años, estudos primarios) 


\begin{tabular}{|c|c|c|c|}
\hline \multirow{2}{*}{$\mathbf{1}^{\mathbf{a}}$ pers. } & $\mathbf{2}^{\mathbf{a}}$ pers. & $\mathbf{3}^{\mathbf{a}} / \mathbf{6}^{\mathbf{a}}$ pers. & $\mathbf{4}^{\mathbf{a}}$ pers. \\
\hline \multirow{2}{*}{ A mi lado (6) } & & Al lado de ellos (1) & \\
\cline { 3 - 4 } & & & $\begin{array}{c}\text { A nuestro lado (1) } \\
\text { Al lado nuestro (1) }\end{array}$ \\
\cline { 4 - 4 } Al lado mía (1) & Al lado tuya (1) & & Al lado nuestra (2) \\
\hline
\end{tabular}

Cadro 21. Alternativas construtivas na locución adverbial nucleada por lado. Corpus ESLORA

(40) De hecho eso fue una cosa de que lo $<$ pau$\mathrm{sa} />$ le pusieron las esposas delante nuestra $<$ pausa_larga/> (muller, 37 años, estudos medios)

Aínda que non é significativo procurar porcentaxes, obsérvase un certo equilibrio entre a variante innovadora e a estrutura frástica ${ }^{48}$.

O corpus permite tamén documentar o vigor que presenta POS en estruturas xeradas pola preposición junto: localízase un só junto de mí fronte a cinco casos como o que segue:

(41) $[\ldots]$ porque ella sabiendo cómo es su hermana $<$ pausa/ $>$ lo que debía de hacer es venir a junto mía $<$ pausa/> y decirme (...) mira ¿qué fue lo que pasó? < pausa larga/> (muller, 54 años, estudos primarios)

Finalmente, debemos destacar que o corpus ESLORA achega tamén datos de posesivos femininos en estruturas nucleadas polo adverbio arredor e polo substantivo lado. Coa primeira destas unidades localízanse cinco construcións que podemos cualificar como esperables (con posesivo reducido anteposto: mi alrededor e outras formas do paradigma), ningún caso de Fprep e / un exemplo de alrededor mía, que se reproduce como (42):

(42) (...) porque siempre tuve buena gente alrededor mía <pausa_larga/> (muller, 54 anos, estudos primarios)

As posibilidades que se documentan con lado aparecen sintetizadas no cadro 21 , en que destacamos as opcións innovadoras.

O corpus achega datos acerca das características dos/as falantes, de interese para o establecemento dunha comparación entre innovadores/as e tradicionais. Neste sentido, parece que as variables xénero e nivel de estudos non se amosan relevantes na selección entre ambas as posibilidades ${ }^{49}$.

Maior interese presenta a exploración da variable idade. Dos/as 14 informantes que constrúen secuencias non innovadoras, 10 teñen máis de 40 anos e os/as outros/as catro arredor de 30. Canto aos/ás que presentan POS, incluídos femininos non concordantes do tipo de al lado mía, unicamente seis teñen máis de 40 anos e tres deles/as son os/as máis novos/ as da nosa submostra, ao seren menores de 30 anos. A media de idade duns/unhas e outros/as presenta así mesmo diferenzas significativas: os/as tradicionais sitúanse en 58,7 anos, os/as innovadores/as, en 42,9 anos.

\section{Síntese final dos datos e proposta de inter- pretación destes desde a perspectiva da mu- danza sintáctica}

Os resultados da análise dos corpus TILG, CORGA, CORILGA e ESLORA, realizada nos apartados 3-6 do traballo, permiten responder do seguinte xeito ás preguntas de investigación formuladas supra, apartado 1.2:

Canto á cuestión formulada no apartado 1.2.1, cómpre sinalar que a expansión da variante innovadora comeza a testemuñarse na escrita en galego nos anos 30 do século XX e nas seguintes unidades dos tipos 1 e 2: enriba, diante e detrás. Nos anos 50 localízase un exemplo de tras (tipo 2), mentres que o seguinte adverbio en ofrecer un exemplo é lonxe (tipo 3). O avance cara ao resto das unidades dos tipos 1-4 prodúcese a partir dos anos 80 do século XX.

Para os adverbios en que se testemuña primeiro, o avance porcentual da variante innovadora é significativo nas persoas do coloquio, especialmente na primeira (cf. supra, cadros

48 En concreto: encima (dúas estruturas con Fprep e dúas con POS); delante (unha e dúas, respectivamente); detrás (tres e dúas, respectivametne); tras (unha de cada).

49 Con estruturas tradicionais: oito mulleres, seis homes. Con estruturas innovadoras: sete mulleres, seis homes. Para a estrutura tradicional: catro falantes con estudos primarios, sete con medios, dous/as universitarios/as; para a estrutura innovadora: seis informantes con estudos primarios, seis con medios, un/unha con universitarios. 
6-17 e gráfico 1). En terceira e sexta persoas, a necesaria condición de [+animado] que xeralmente acompaña o emprego de POS (con algunhas excepcións, reproducidas supra, apartado 4.2.3.1) impide a equivalencia plena entre POS e Fprep e pode ser un factor explicativo para a máis lenta extensión da innovación.

No referido ao segundo fenómeno, isto é, a selección da variante non concordada en unidades dos tipos 5 e 6 , a análise permite testemuñala tamén de xeito temperán: nos anos 50 do século XX localízanse xa exemplos con redor. A partir dos anos 80 do século XX vanse incorporando á innovación as locucións nucleadas polas formas de valor locativo carón, rente e lado. A ruptura da concordancia prodúcese tamén en complexos adverbiais situados en ámbitos semánticos diferentes dos locativos; así, esta pasa a ser posible en construcións con través (con significado abstracto) e favor. Porén, os testemuños do avance son moi limitados en termos cuantitativos e non poden ser analizados porcentualmente.

Canto ás preguntas da investigación formuladas supra, nos apartados 1.2.2 e 1.2.3, sinalarase que tanto TILG como CORGA e CORILGA ofrecen case unicamente POS de morfoloxía feminina na frase adverbial, e ESLORA testemuña a identidade, a este respecto, entre galego e castelán de Galicia. No relativo á explicación desta morfoloxía, anteriormente (cf. supra, apartado 3.4) ofreceuse unha hipótese novidosa, compatible cos datos dos corpus examinados e que permite abordar conxuntamente os datos de ambas as linguas.

Ocupámonos finalmente da interpretación dos dous fenómenos que se analizan, o exemplificado en (2) e o testemuñado en (4), de acordo coa construción conceptual exposta anteriormente (cf. supra, apartado 2, cadro 2). Parece evidente, en ambos os casos, o feito de situármonos na fase II ou de coexistencia entre as dúas variantes, e isto ao longo de todo o período estudado (séculos XX e primeiras décadas de XXI). Canto á segunda das innovacións, aquela referida á non concordancia do posesivo en estruturas de natureza nominal, non é doado postular un avance desta máis alá da fase de indicador. Exemplos como ao lado miña e similares parecen axeitarse aos requisitos sinalados a este respecto en Del Barrio (2018: 43) no seu tratamento do concepto: non semellan estar conscientemente controlados polos/as falantes e non presentan variacións estilísticas. Resulta difícil prognosticar que se poida ir producindo un avance nestas estruturas cara á condición de marcadores; aínda máis, a vulneración da regra da concordancia gramatical que comportan fai máis plausible a súa futura categorización como estereotipos. Ata o momento actual, porén, non cremos que se teña producido tal reinterpretación, quizais por causa de estas construcións pasaren desapercibidas na descrición gramatical do galego (téñase en conta que só de maneira moi recente o fenómeno agroma na análise no diasistema do español ${ }^{50}$ ).

Canto á determinación, en estruturas do tipo de diante miña e similares, da súa condición de indicadores, marcadores ou estereotipos, esta reviste unha maior complexidade. Cumpriría enfrontar unha análise máis polo miúdo da variación entre as alternativas exemplificadas en (1) e (2), abordando, alén dos aspectos aquí recollidos (percorrido temporal, importancia cuantitativa por épocas e formas, persoa gramatical, condición de [ \pm animado] do referente), algúns outros, ligados á caracterización lingüística global dos textos en que os exemplos ocorren. No entanto, como resposta preliminar e a falta dun estudo doutro tipo, cremos posible postular que a innovación se atopou na fase de indicador ata os anos 80 do século XX, aínda que algunhas ocorrencias anteriores, como o lonxe túa reproducido en (22), xa poidan responder a unha expansión cualitativa do fenómeno cara aos tipos 3-6 (cf. supra, cadro 3) que probablemente se produciu xa con independencia de que esta combinación fose ou non posible na lingua oral. A partir dos anos $80, \operatorname{logo}$ do tratamento da variación en propostas gramaticais como as mencionadas supra (apartado 3.3), lexitimadoras da alternancia entre Fprep e POS, consideramos que a opción innovadora debe ser analizada xa como un marcador, en expansión cuantitativa e cualitativa como estratexia para converter as obras literarias en que aparece en máis "enxebres", ou máis "lingüisticamente tradicionais".

50 Dos diversos traballos que se ocupan da presenza do posesivo na frase adverbial do español, só os seguintes abordan a descrición do fenómeno de non concordancia nas locucións adverbiais: Eddington (2017: 53), Salgado e Bouzouita (2017: 782, 787) e Marttinen Larsson (2021). 
Para postular con maior firmeza a efectiva existencia desta primeira avaliación positiva deberiamos determinar que textos e autores/ as optan pola innovación e cales non, así como achegar, se for posible, algunha información acerca de posibles intervencións sobre os textos, realizadas nas editoriais e ligadas ao proceso de corrección dos orixinais nunha fase previa á publicación. Sería moi interesante saber, por exemplo, se as persoas que vixiaron e vixían a calidade lingüística nas nosas editoriais mantiveron e manteñen a estrutura innovadora cando esta aparece, ou se a substitúen, ou mesmo se a introducen cando non ocorre no orixinal. Neste sentido, parece significativa a vinculación de boa parte dos exemplos innovadores á narrativa xurdida a partir dos anos 80 do século XX, xusto nun momento temporal de grande expansión cuantitativa, en que a escola comeza a demandar textos en galego para as aulas de lingua. A asociación entre as propostas gramaticais do contorno ILG e a idea de que a escrita debe achegarse o máis posible á oralidade é ben coñecida e foi reiteradamente descrita (véxase por exemplo, Alonso Pintos 2002 e 2006), e puido influír, desde o noso punto de vista, na expansión da innovación e na súa transformación de indicador a marcador.
Fronte a esta interpretación desde arriba da mudanza, a análise do fenómeno como castelanismo sintáctico (Freixeiro Mato 2002, 2009, entre outros) procura, cremos, a súa conversión en estereotipo, como paso previo a unha fase III en que debera triunfar a variante conservadora e desaparecer a innovación. Dado que esta proposta de mudanza desde arriba foi formulada nos primeiros anos do milenio, parece prematuro tratar de coñecer o seu alcance mediante os corpus galegos analizados no presente traballo, pois as evidencias que estes achegan son, na súa gran maioría, anteriores temporalmente. No entanto, os 83 exemplos localizados, no corpus CORGA e entre 2004 e 2016, do tipo de (43), e mais os 39 semellantes a (44), non avalan en absoluto a hipótese de que a innovación que nos ocupa estea iniciando un proceso de estereotipificación:

(43) Eis a estatua do Trobeiro. Por fin a teño diante miña (X.M. Lema, Costa do solpor, 2013; novela)

(44) Mentres suspira, énchenselle os ollos de bágoas. Finalmente, arrima a porta con coidado, ata que a visión do seu irmán desaparece detrás súa (D. Ameixeiras, Matarte lentamente, 2013; novela)

\section{Referencias bibliográficas}

Álvarez Blanco, Rosario (coord.) (1995): Atlas lingüístico galego. Tomo II: Morfoloxía non verbal. A Coruña: Fundación Pedro Barrié de la Maza, Conde de Fenosa.

Alonso Pintos, Serafín (2002): Para unha historia do estándar galego. As propostas do período 1966-1980. Madrid: UNED.

- (2006): O proceso de codificación do galego moderno (1950-1980). A Coruña: Fundación Pedro Barrié de la Maza.

Álvarez Blanco, Rosario e Xosé Xove (2002): Gramática Galega. Vigo: Galaxia.

Bertolotti, Virginia (2014): "Pronombres posesivos en el español rioplatense: tres casos de reanálisis", Traslaciones. Revista Hispanoamericana de Lectura y Escritura 1/1, pp. 56-64, https://revistas.uncu. edu.ar/ojs/index.php/traslaciones/article/view/194.

(2017): "Pronombres posesivos y cambios gramaticales en español: Análisis en la variedad rioplatense", en Concepción Company Company e Norohella Huerta Flores (eds.): La posesión en la lengua española. Madrid: CSIC, pp. 325-349.

Bouzouita, Miriam (no prelo): "The diatopic distribution of the use of possessive pronouns instead of verbal prepositional phrase complements in Spanish".

Braunmüller, Kurt; Steffen Höder e Karoline Kuhl (eds.) (2014): Stability and Divergence in Language Contact. Factors and Mechanisms. Amsterdam: John Benjamins.

Breithbarth, Anne; Christopher Lucas, Sheila Watts e David Willis (eds.) (2010): Continuity and Change in Grammar. Amsterdam: John Benjamins.

Casanova, Vanessa (2020): "El uso del complemento posesivo verbal por el complemento de régimen preposicional en español actual”, en Miriam Bouzouita e Matti Marttinen Larsson (eds.), Moderna Språk 114/3 (Special issue on possessive constructions in Romance), pp. 264-301, http://hdl.handle.net/1854/ LU-8638372.

Conde Silvestre, Juan Camilo (2007): Sociolingüistica histórica. Madrid: Gredos. 
Centro Ramón Piñeiro para a Investigación en Humanidades: Corpus de Referencia do Galego Actual (CORGA) [3.2], http://www.cirp.gal/corga// [consulta: 01/2018-04/2021].

De Benito Moreno, Carlota e Ana Estrada Arráez (2016): "Introducción. Si Alvar levantara la cabeza: cómo tratar con informantes virtuales", Revista internacional de lingüística iberoamericana 28, pp. 7-17.

(2018): “Aproximación metodológica al estudio de la variación lingüística en las interacciones digitales", REDD: Revista de estudios del discurso digital 1, pp. 74-122, DOI: https://doi.org/10.24197/ redd.1.2018.74-122.

Del Barrio de la Rosa, Florencio (2018): Espacio variacional y cambio lingüístico en español. Madrid: Visor Libros.

Döhla, Hans-Jörg (2014): "Diachronic convergence and divergence in differential object marking between Spanish and Portuguese", en Kurt Braunmüller, Steffen Höder e Karoline Kuhl (eds.) (2014): Stability and Divergence in Language Contact. Factors and Mechanisms. Amsterdam: John Benjamins, pp. 265-289.

Eddington, David (2017): "Nominalized adverbs in Spanish: the intriguing case of detrás mío and its cohorts", Research in Corpus Linguistics 5, pp. 47-55, DOI: https://doi.org/10.32714/ricl.05.04.

Enrique-Arias, Andrés (2010): "On language contact as an inhibitor of language change", en Anne Breithbarth, Christopher Lucas, Sheila Watts e David Willis (eds.) (2010): Continuity and Change in Grammar. Amsterdam: John Benjamins, pp. 97-118.

Vázquez Rozas, Victoria (dir.): Corpus para el estudio del español oral (ESLORA). Santiago de Compostela: Universidade de Santiago de Compostela, http://eslora.usc.es/ [consulta: 01/2018-04/2021].

Fernández Rei, Francisco (coord.) (1990): Atlas lingüístico galego. Tomo I: Morfoloxía verbal. A Coruña: Fundación Pedro Barrié de la Maza, Conde de Fenosa.

Freixeiro Mato, Xosé Ramón (2001): "Interferencia e niveis de uso dalgunhas construcións con pronome posesivo en galego", Revista Galega de Filoloxía 2: pp. 69-88, http://hdl.handle.net/2183/2576.

(2009): Lingua de calidade. Vigo: Xerais.

Hoff, Mark (2020): "Cerca mío o cerca de mí? A variationist analisis of Spanish locative + possessive on Twitter", Studies in Hispanic and Lusophone Linguistics 13/1, pp. 51-78, DOI: https://doi.org/10.1515/ shll-2019-2017.

Jakob, Daniel e Johannes Kabatek (eds.) (2001): "Introducción: lengua, texto y cambio lingüístico en la Edad Media", en Daniel Jakob e Johannes Kabatek (eds.): Lengua medieval y tradiciones discursivas en la Península Ibérica. Frankfurt am Main / Madrid: Vervuert / Iberoamericana, pp. VII-XVII.

Kühl, Karoline e Kurt Braunmüller (2014): "Linguistic stability and divergence: An extended perspective", en Kurt Braunmüller, Steffen Höder e Karoline Kuhl (eds.): Stability and Divergence in Language Contact. Factors and Mechanisms. Amsterdam: John Benjamins, pp. 13-38.

Labov, William (2001): Principles of Linguistic Change. Social Factors. Oxford: Blackwell.

Lucchesi, Dante (2012): “O contato entre línguas e a origem do português brasileiro", en Eva Gugenberger, Henrique Monteagudo e Gabriel Rei-Doval (eds.): Contacto de linguas, hibrididade, cambio:contextos, procesos e consecuencias. Santiago de Compostela: Consello da Cultura Galega, pp. 191-221.

Lucchesi, Dante; Alan Baxter e Ilza Ribeiro (coords.) (2009): O Português Afro-Brasileiro. Salvador de Baia: EDUFBA.

Mariño Paz, Ramón (2017): "Breve reflexión histórica sobre o cambio inducido por contacto castelanizante en galego”, en Xosé Luís Regueira e Elisa Fernández Rei (eds.): Estudos sobre o cambio lingüístico no galego actual. Santiago de Compostela: Consello da Cultura Galega, pp. 45-62.

Marttinen Larsson, Matti (2021): "Modelling incipient probabilistic grammar change in real time: the grammaticalisation of possessive pronouns in European Spanish locative adverbial constructions", Corpus Linguistics and Linguistic Theory, https://doi.org/10.1515/cllt-2021-0030.

Marttinen Larsson, Matti e Laura Álvarez López (2017): “Delante suyo vs. delante de él: el uso de las locuciones adverbiales locativas desde una perspectiva diacrónica y diatópica”, Signo y Seña 31, pp. 85-104, DOI: https://doi.org/10.34096/sys.n31.3827.

Marttinen Larsson, Matti e Miriam Bouzouita (2018): "Encima de mí vs. encima mío: un análisis variacionista de las construcciones adverbiales locativas con complementos preposicionales y posesivos en Twitter", Moderna Språk 112/1, pp. 1-39, https://ojs.ub.gu.se/index.php/modernasprak/article/view/4331/3507.

Marttinen Larsson, Matti e Miriam Bouzouita (2018): "Female morphology in possessive complements of adverbial constructions in Andalusian varieties". Comunicación presentada ao Congreso "Possesive Constructions in Romance" (PossRom 2018), Universidade de Gante, xuño de 2018. 
Martins, Ana Maria (2015): "Variação sintáctica no português quinhentista: a colocação dos pronomes clíticos”, Estudos de lingüistica galega 7, pp. 83-94, DOI: https://doi.org/10.15304/elg.7.2373.

Matras, Yaron (2009): Language Contact. Cambridge: Cambridge University Press.

Meilán García, Antonio (1998): Construcciones locativas y cuantitativas. Madrid: Arco/Libros.

Pons Rodríguez, Lola (2006): "Una reflexión sobre el cambio lingüístico en el español del siglo XV”, en Juan de Dios Luque Durán e Andrés de Molina Redondo (eds.): Actas del V Congreso andaluz de lingüistica general: homenaje al profesor José Andrés de Molina Redondo. Granada: Granada Lingüística, vol. 3: pp. 1563-1568.

Real Academia Galega (2012): Diccionario da lingua galega. A Coruña: Real Academia Galega, https:// academia.gal/dicionario [consulta: 01/2018-04/2021].

Regueira Fernández, Xosé Luis (dir.): Corpus oral informatizado da lingua galega (CORILGA). Santiago de Compostela / Vigo: Instituto da Lingua Galega / Atlantic-Universidade de Vigo, http://ilg.usc.es/ corilga/ [consulta: 01/2018-04/2021].

Salgado, Hugo e Miriam Bouzouita (2017): "El uso de las construcciones de adverbio locativo con pronombre posesivo en el español peninsular: un primer acercamiento diatópico", Zeitschrift fur Romanische Philologie 133/3, pp. 766-794, DOI: https://doi.org/10.1515/zrp-2017-0038.

Silva Domínguez, Carme (1995): "As estructuras adverbiais do tipo de diante miña", Cadernos de lingua 11, pp. 5-21, http://publicacionsperiodicas.academia.gal/index.php/Cadernos/article/view/529/543.

(2002): Frases nominais con posesivo en galego. Estructura e valores referenciais (Aanexo $\mathrm{n}^{\circ} 50$ de Verba. Anuario Galego de Filoloxía). Santiago de Compostela: Servizo de Publicacións.

- (2020): "El posesivo en construcciones de valor locativo de la lengua gallega: innovación lingüística e interferencia a partir del análisis de corpus contemporáneos", en Miriam Bouzouita e Matti Marttinen Larsson (eds.), Moderna Språk 114/3 (Special issue on Possessive constructions in Romance), pp. 226263, https://ojs.ub.gu.se/index.php/modernasprak/article/view/5251.

Santamarina, Antón (dir.); Ernesto González Seoane e María Álvarez de la Granja: Tesouro Informatizado da Lingua Galega (TILG). (Versión 4.1). Santiago de Compostela: Instituto da Lingua Galega, http://ilg. usc.gal/TILG/ [consulta: 01/2018-09/2020]. 